\title{
The Marginal Zone/Layer I as a Novel Niche for Neurogenesis and Gliogenesis in Developing Cerebral Cortex
}

\author{
Marcos R. Costa, ${ }^{1,2,3}$ Nicoletta Kessaris, ${ }^{4}$ William D. Richardson, ${ }^{4}$ Magdalena Götz, ${ }^{1,5 *}$ and Cecilia Hedin-Pereira ${ }^{2,3 *}$ \\ ${ }^{1}$ National Research Center for Environment and Health, Institute for Stem Cell Research, 85764 Neuherberg/Munich, Germany, ${ }^{2}$ Instituto de Biofísica \\ Carlos Chagas Filho, Universidade Federal do Rio de Janeiro, Rio de Janeiro, Brazil, 21941-902, ${ }^{3}$ Laboratório de Neuroanatomia Celular, Departamento de \\ Anatomia, Instituto de Ciências Biomédicas, Universidade Federal do Rio de Janeiro, Rio de Janeiro, Brazil 21941-590, ${ }^{4}$ Wolfson Institute for Biomedical \\ Research and Department of Biology, University College London, London WC1E 6BT, United Kingdom, and 5Physiological Genomics, Institute of \\ Physiology, University of Munich, 80336 Munich, Germany
}

The cellular diversity of the cerebral cortex is thought to arise from progenitors located in the ventricular zone and subventricular zone in the telencephalon. Here we describe a novel source of progenitors located outside these two major germinative zones of the mouse cerebral cortex that contributes to neurogenesis and gliogenesis. Proliferating cells first appear in the preplate of the embryonic cerebral cortex and further increase in the marginal zone during mid and late neurogenesis. The embryonic marginal zone progenitors differ in their molecular characteristics as well as the size and identity of their clonal progeny from progenitors isolated from the ventricular zone and subventricular zone. Time-lapse video microscopy and clonal analysis in vitro revealed that the marginal zone progenitor pool contains a large fraction of oligodendrocyte or astrocyte progenitors, as well as neuronal and bipotent progenitors. Thus, marginal zone progenitors are heterogenous in regard to their fate specification, as well as in regard to their region of origin (pallial and subpallial) as revealed by in vivo fate mapping. The local environment in the marginal zone tightly regulates the size of this novel progenitor pool, because both basement membrane defects in laminin $\gamma 1^{-/-}$mice or alterations in the cellular composition of the marginal zone in Pax6 Small Eye mutant mice lead to an increase in the marginal zone progenitor pool. In conclusion, we have identified a novel source of neuronal and glial progenitors in the marginal zone of the developing cerebral cortex with properties notably distinct from those of ventricular zone and subventricular zone progenitors.

Key words: marginal zone; cerebral cortex; development; neurogenesis; gliogenesis; Reelin; basement membrane

\section{Introduction}

For many years, the neurons of the cerebral cortex were thought to derive exclusively from neuroepithelial cells and migrate along radial glial fibers to their final position in the cortical layers (Berry and Rogers, 1965; Rakic, 1972; Caviness and Sidman, 1973). Despite some evidence for tangential dispersion of cells in the developing cerebral cortex (Price and Thurlow, 1988; Walsh and Cepko, 1988), it was only 10 years ago that the tangential migration from the ganglionic eminences (GEs) was shown to contribute to the generation of cortical GABAergic interneurons in different mammalian species (Anderson et al., 1997; Lavdas et al.,

\footnotetext{
Received Jan. 19, 2007; revised Aug. 3, 2007; accepted Aug. 16, 2007.

This work was supported by grants from the Deutsche Forschungsgemeinschaft, Bundesministerium für Bildung und Forschung, and the Bavarian State Ministry of Sciences, Research, and the Arts (M.G.) and by Coordenação de Aperfeiçoamento de Pessoal de Nível Superior/Deutscher Akademischer Austausch Dienst and Programa de Formação em Pesquisa Médica (MD/PhD) scholarships (M.R.C.). We are very grateful to Uli Meyer for the laminin $\gamma$ IIImutant brains and to Rob Hevner, Francois Guillemot, David Rowitch, Jhumku Kohtz, Jack Price, and André Goffinet for antibodies. We also thank Maira Monteiro Fróes, Benedikt Berninger, and Leanne Godinho for excellent comments on this manuscript and Angelika Waiser and Andrea Steiner-Mezzadri for expert technical help.

${ }^{*}$ M.G. and C.H.-P. contributed equally to this work.

Correspondence should be addressed to either Marcos R. Costa or Magdalena Götz, National Research Center for Environment and Health, Institute for Stem Cell Research, Ingolstädt Landstrasse 1, 85764 Neuherberg/Munich Germany. E-mail:marcos.costa@gsf.de or magdalena.goetz@gsf.de.

D01:10.1523/JNEUROSCI.2418-07.2007
}

Copyright $\odot 2007$ Society for Neuroscience $\quad 0270-6474 / 07 / 2711376-13 \$ 15.00 / 0$
1999; Wichterle et al., 2001; Letinic et al., 2002). More recently, the contribution of radial glial cells and subventricular zone (SVZ) cells to the generation of specific types of neurons in the developing cerebral cortex (Malatesta et al., 2003; Haubensak et al., 2004; Miyata et al., 2004; Nieto et al., 2004; Noctor et al., 2004; Wu et al., 2005) has further supported the concept that diverse progenitor subtypes bring about the great diversity of cortical neurons. In addition, astrocytes and oligodendrocytes develop in sequential waves in the cerebral cortex (Choi, 1988a; Levison and Goldman, 1993; Marin-Padilla, 1995; Tekki-Kessaris et al., 2001; deAzevedo et al., 2003) and originate from distinct progenitors (Kessaris et al., 2006). Thus, the cellular diversity in the cerebral cortex is the outcome of the progenitor heterogeneity within distinct germinative niches.

One cohort of proliferating cells in the embryonic cortex however has still not been examined. Mitotic figures (rodents: Raedler and Raedler, 1978; Marin-Padilla, 1985; Valverde et al., 1995; humans: Choi, 1988b; Bystron et al., 2006) as well as DNA synthesis as indicated by incorporation of the DNA base analog bromodeoxyuridine (BrdU) (Götz and Bolz, 1992; Hedin-Pereira et al., 2000) (E. de Moraes and C. Hedin-Pereira, personal communication) have been observed in the marginal zone (MZ), the outermost layer of the cerebral cortex. However, the identity and progeny of these cells have so far been neglected. This is particu- 
larly surprising, because cells in the MZ are known to play crucial roles during development, such as orchestrating the formation of cortical layers (for review, see Tissir and Goffinet, 2003) and contributing to the GABAergic interneurons in the cerebral cortex (Meyer et al., 1998; Lavdas et al., 1999; Ang et al., 2003; Tanaka et al., 2006). MZ cells have also been shown to guide cortical afferents to their targets (Marin-Padilla, 1978; McConnell et al., 1989; Del Rio et al., 1997) and develop a transient neuronal circuit of crucial importance for setting up the mature circuitry among cortical plate (CP) neurons (Schwartz et al., 1998; Friauf and Shatz, 1991; Ghosh and Shatz, 1992). Moreover, several lines of evidence suggest a dual origin for astroglial cells, namely from the ventricular but also the marginal zone, in the developing human (Marin-Padilla, 1995; deAzevedo et al., 2003) and rodent cerebral cortex (Choi, 1988a), but it is unknown whether those astroglial cells could be locally generated in the cortical surface. Elucidating the nature of proliferation in the $\mathrm{MZ}$ is therefore of crucial importance.

\section{Materials and Methods}

Animals. Most experiments were performed with timed-pregnant C57BL/6J mice, with the day of the vaginal plug considered to be embryonic day 0 (E0) and the day of birth as postnatal day 0 (P0). $\mathrm{Pax}^{\mathrm{Sey}}$ mice were maintained as heterozygotes on a mixed C57BL/6J $\times$ DBA/2J background, and laminin $\gamma 1 \mathrm{III} 4^{-1-}$ mice were kept on C57BL/6J/SV129 background. Crossing of heterozygous animals allowed for the examination of wild-type (WT) and homozygous mutant embryos $(-/-)$ from the same litter to avoid potential differences in development. E1-Ngn2Cre (enhancer 1-neurogenin 2-enterobacteria phage P1, cyclization recombinase) (Berger et al., 2004) and Emx1 (empty spiracles homolog 1)::Cre mice (Iwasato et al., 2000) were crossed with C57BL/6J mice and the transgenic embryos were analyzed. Gsh2 (genomic screened homeobox)-Cre, Nkx2.1 (NK2 transcription factor-related 2.1)-Cre, and Emx1-Cre mice (Kessaris et al., 2006) were crossed with Rosa26-yellow fluorescent protein (Rosa-YFP) (Srinivas et al., 2001). Animals were maintained on a 12 h (7:00 A.M. to 7:00 P.M.) light/dark cycle. All experimental procedures were done in accordance with Society for Neuroscience and European Union guidelines and were approved by our institutional animal care and use committees.

Histology and immunohistochemistry. Timed-pregnant mice were killed by cervical dislocation. Embryos were removed by hysterectomy and transferred into HBSS (Invitrogen, Carlsbad, CA) with $10 \mathrm{~mm}$ HEPES. Embryonic brains were removed and fixed in $4 \%$ paraformaldehyde (PFA) (in PBS) for $2 \mathrm{~h}$ (E14 brains), $3 \mathrm{~h}$ (E16 brains), or $4 \mathrm{~h}$ (E18 brains) at $4^{\circ} \mathrm{C}$. After a brief washing step with PBS, the tissue was incubated at $4^{\circ} \mathrm{C}$ in $30 \%$ sucrose solution (in PBS) overnight. After cryoprotection was completed, the tissue was embedded in O.C.T. (Tissue-Tek; Sakura Finetek Europe, Zoeterwoude, The Netherlands) within an embedding mold and frozen on dry ice. Sections $(20 \mu \mathrm{m})$ were cut using a cryostat, collected on SuperFrost Plus microscope slides, and stored at $-20^{\circ} \mathrm{C}$.

Sections or coverslips with cultured cells (see below) were incubated in primary antibody overnight at $4^{\circ} \mathrm{C}$ in $0.5 \%$ Triton X-100 and $10 \%$ normal goat serum in PBS. Primary antibodies used included anti-BrdU [rat, 1:100 (Abcam, Cambridge, UK); $30 \mathrm{~min} 2 \mathrm{~N} \mathrm{HCl}, 30$ min borate buffer, pH 8.5], anti-phosphohistone3 (rabbit, 1:200; Biomol, Plymouth Meeting, PA), anti-Tbr2 (T-box brain gene 2) (rabbit, 1:2000; provided by R. Hevner, University of Washington, Seattle, WA), anti-Pax6 (paired box gene 6) (rabbit, 1:200; Covance Research Products, Berkeley, CA), antiOlig2 (oligodendrocyte transcription factor 2) (rabbit, 1:1000; provided by D. Rowitch, University of California, San Francisco, San Francisco, CA), anti-Cre (rabbit, 1:500; Covance Research Products), anti-pan-Dlx (distal-less homeobox) (rabbit, 1:750; provided by J. Kohtz, Northwestern University, Chicago, IL), anti-Mash1 (mammalian achaete-schute homolog 1) (mouse IgG1, 1:100; provided by F. Guillemot, National Institute for Medical Research, London, UK), anti-CD31 (rat, 1:10; BD PharMingen, San Jose, CA), anti- $\beta$ III-tubulin (mouse IgG2b, 1:100;
Sigma, St. Louis, MO), anti-green fluorescent protein (GFP) [rabbit, 1:500 (Clontech, Mountain View, CA); chicken, 1:500 (Sigma)], antiGFAP (mouse IgG1, 1:200; Sigma), anti-nestin (mouse IgG1, 1:4; Developmental Studies Hybridoma Bank, University of Iowa, Iowa City, IA), anti-O4 (mouse IgM, 1:200; provided by J. Price, King's College London, London, UK), anti-NG2 (rabbit, 1:250; Chemicon), anti-PDGF receptor $\alpha$ (PDGFR $\alpha$ ) (rabbit, 1:10; Zytomed, Berlin, Germany), anti-GABA (rabbit, 1:500; Sigma), anti-GAD65/67 (rabbit, 1:500; Chemicon), and anti-Reelin (mouse, 1:500; provided by A. Goffinet, Université Catholique de Louvain, Brussels, Belgium). Nuclei were visualized with 4', 6'-diamidino-2-phenylindole (DAPI; Sigma) by incubating sections for $10 \mathrm{~min}$ with a concentration of $0.1 \mu \mathrm{g} / \mathrm{ml}$ DAPI in PBS. Fluorescent secondary antibodies were used according to the protocol of the manufacturer [Jackson ImmunoResearch (West Grove, PA) or Southern Biotechnology, Birmingham, AL). Sections or coverslips were mounted in Aqua Poly/Mount (Polysciences, Northampton, UK) and analyzed using Zeiss (Oberkochen, Germany) Axioplan 2 and Olympus Optical (Tokyo, Japan) confocal laser scanning microscopes.

Before BrdU immunostaining, timed-pregnant mice or postnatal animals were injected intraperitoneally with $\mathrm{BrdU}(50 \mathrm{mg} / \mathrm{kg}$ body weight) and killed $30 \mathrm{~min}$ or $1 \mathrm{~h}$ after the injection. Alternatively, adult mice received $\mathrm{BrdU}$ in the drinking water $(1 \mathrm{mg} / \mathrm{ml})$ for 2 weeks, followed by 2 weeks without BrdU treatment.

Quantification of proliferating cells in vivo. The quantification of proliferating cells in the MZ was performed in sections of the cerebral cortex at E14, E16, and E18 at rostral, intermediate, and caudal levels stained with antibodies against BrdU and phosphorylated form of histone $\mathrm{H} 3$ (PH3). The area analyzed was restricted to the laterodorsal aspect of the dorsal telencephalon, and its tangential extension was defined by the corticostriatal sulcus laterally and the cingulate cortex medially (supplemental Fig. 1, available at www.jneurosci.org as supplemental material). For the quantification of $\mathrm{PH} 3$-postitive cells in the cortex, the same tangential extension of MZ, ventricular zone (VZ), and SVZ described above were analyzed. Radially, only the first four MZ DAPI-positive nuclei above the cortical plate border were considered to exclude meningeal cells (The Boulder Committee, 1970). Meningeal tissue was readily recognizable by DAPI staining the horizontal disposition of its cells and its fibrous appearance in bright field. The pia mater could generally be recognized approximately six nuclei away from the cortical plate surface.

Primary cell culture. Embryonic brains were isolated from E15 and E18 timed-pregnant mice as described above. The hemispheres were separated and the meninges were removed. Brains were removed in sterile conditions and cut coronally at $200 \mu \mathrm{m}$ using a tissue chopper (McIlwain). After $0.5 \mathrm{~h}$ in HBSS with $10 \mathrm{~mm}$ HEPES at $4^{\circ} \mathrm{C}$, the lateral telencephalic wall of E15 coronal sections was microdissected out in its radial axis so that the bottom part contained the ventricular, subventricular, and intermediate (IZ) zones (E15 VZ/SVZ) and the top one the CP and marginal zone cells (E15 MZ/CP). E18 cortex was microdissected out in three parts: ventricular and subventricular zones (E18 VZ/SVZ); intermediate zone and cortical plate (E18 IZ/CP); and marginal zone (E18 $\mathrm{MZ}$ ). After a brief centrifugation step to remove the HEPES, $1 \mathrm{ml}$ of trypsin $0.05 \%$ EDTA solution (Invitrogen) was added to digest the tissue for $15 \mathrm{~min}$ at $37^{\circ} \mathrm{C}$. Trypsin activity was stopped by adding $2 \mathrm{ml}$ of DMEM (Invitrogen) supplemented with $10 \%$ fetal calf serum (FCS) (Sigma) and penicillin/streptomycin $(100 \mathrm{U} / \mathrm{ml}$ penicillin, $100 \mathrm{mg} / \mathrm{ml}$ streptomycin; Invitrogen). Cells were mechanically dissociated with a fire-polished and FCS-coated Pasteur pipette. The cells were collected twice from the supernatant after centrifugation for $5 \mathrm{~min}$ at $1000 \mathrm{rpm}$ $(172 \times g)$, followed by resuspension in DMEM $(10 \%$ FCS, $1 \%$ penicillin/ streptomycin). Cells were counted with the help of a Neubauer chamber, plated at a density of $5 \times 10^{5}$ cells per well in a 24 -well plate on poly-Dlysine (PDL)-coated glass coverslips, and incubated at $37^{\circ} \mathrm{C}$ and $5 \% \mathrm{CO}_{2}$.

Retroviral transduction was performed $2-3 \mathrm{~h}$ after plating using low titers of vesicular stomatitis virus G-protein pseudotyped retroviruses containing the chicken matrix metalloproteinase plasmid (Hack et al., 2004). This procedure infects a small number of progenitor cells whose progeny can be detected after a period of time in culture as distinct clusters of cells by fluorescence microscopy. After $1 \mathrm{~d}$ in vitro (DIV), the medium was removed, and $3 \times 10^{5}$ or $1 \times 10^{5}$ E14 cortical cells in 
DMEM/10\% FCS were added to E15 MZ/CP and E15 VZ/SVZ cultures, respectively, to minimize cell death especially in MZ/CP cell culture. Two hours later, DMEM/F-12 (Invitrogen) supplemented with B27 was added in equal volume to decrease the serum concentration to $5 \%$. To exclude the possibility of viral transduction of the E14 cortical cells added $1 \mathrm{~d}$ after starting the MZ cultures, we performed control experiments in which these cells were grown in the medium removed from VZ/SVZ and MZ cell culture after 1 DIV. We could not detect GFP-positive cells even by using retroviral titers up to 10 times higher than in our clonal analyses, indicating that the virally transduced cells correspond to the cell types infected on the first day, i.e., MZ or VZ/SVZ cells. Before fixation, cells were briefly washed with PBS and then fixed for $15 \mathrm{~min}$ in 4\% PFA. After three washes with PBS at room temperature, cells were processed for immunohistochemistry as described above.

For the clonal analysis in vitro, all clones per coverslip were assessed for the number of cells they contained and the identity of these cells. The low viral titer used to transduce the cells in our experiments allowed us to infer that each cluster (number of clusters per coverslip: $\mathrm{MZ} / \mathrm{CP}$ cell culture, $22 \pm 12$; VZ/SVZ cell culture, $25 \pm 15$; mean \pm SEM from four independent experiments) is derived from one single progenitor cell and can be defined as an individual clone (Williams et al., 1991; Haubst et al., 2004). This low number of clusters resulted in observation of maximally one cluster within a $20 \times$ magnification field $(\sim 1$-mm-diameter field of view), and coverslips in which more than one cell cluster was visualized with a $20 \times$ objective were discarded. Furthermore, timelapse experiments $(n=6)$ confirmed that cells derived from a single progenitor maintain a close proximity $(<300 \mu \mathrm{m})$, and there is no mixture of cells migrating from other regions (supplemental Fig. 4 and movie, available at www.jneurosci.org as supplemental material). Clones were classified according to the expression of GFP and the neuronal marker $\beta$ IIItubulin (Tuj1), oligodendroglial O4, and astroglial GFAP markers. Immunoreactivity for these markers was revealed with secondary antibodies with different conjugated fluorophores, allowing the identification of three types of clones: pure neuronal (all cells stained for Tuj1), pure glial (absence of Tuj1-positive cells and immunoreactivity for either $\mathrm{O} 4$ or GFAP), and mixed clones (at least one Tuj1positive cell and one O4- or GFAP-positive cell). For the analysis of glial cell types within mixed and pure glial clones, the Tuj1 immunoreactivity was omitted, so that we could visualize $\mathrm{O} 4$ and GFAP with different fluorophores together with GFP. The mean number of neuronal and glial cells within different types of clones was plotted and is shown as mean \pm

SEM. Data were derived from at least three experimental batches with two to four coverslips analyzed per experiment.

Neurosphere cultures. E15 MZ/CP, E15 VZ/SVZ, E18 VZ/SVZ, E18 IZ/CP, E18 MZ, P8 layer 1, and P8 SVZ cells were dissected and dissociated as described above and grown in DMEM/F-12 supplemented with

$J$ $E, F, H-I, 25 \mu \mathrm{m}$.
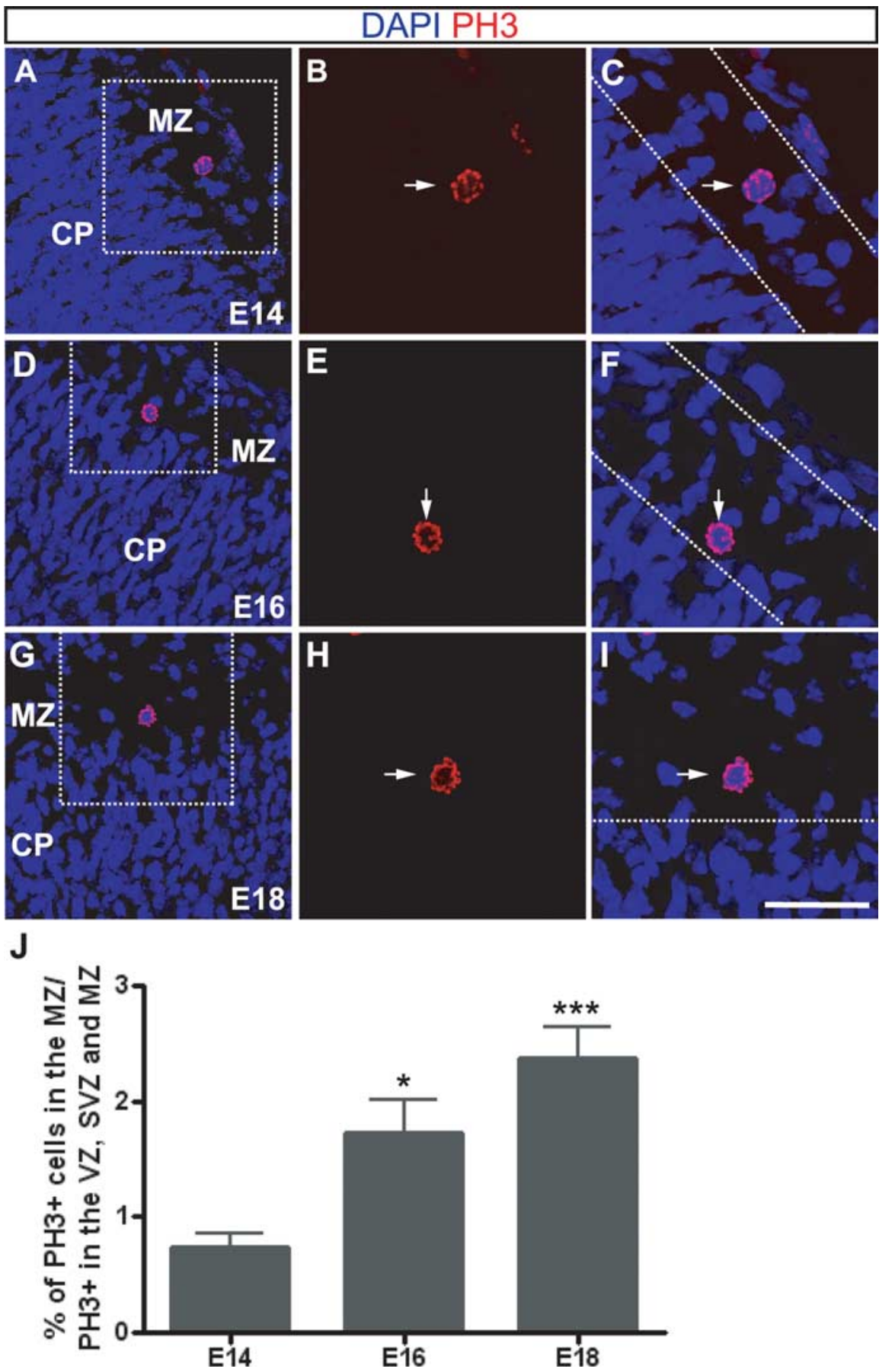

Figure 1. Cell proliferation in the embryonic marginal zone. $A-I$, Coronal sections immunolabeled for PH3 (red) display cells in the MZin E14 $(\boldsymbol{A}-\boldsymbol{C}), \mathrm{E} 16(\boldsymbol{D}-\boldsymbol{F})$, and E18 $(\boldsymbol{G}-\boldsymbol{I})$ cortices. DAPI nuclear staining (blue) reveals the border between MZ and $(P$ as well as the $M Z$ and the pial surface (dashed lines in $\boldsymbol{C}, \boldsymbol{F}, \boldsymbol{I})$. Boxed areas in $\boldsymbol{A}, \boldsymbol{D}$, and $\mathbf{G}$ are enlarged in $\boldsymbol{B}, \boldsymbol{C}, \boldsymbol{E}, \boldsymbol{F}$, and $\boldsymbol{H}-\boldsymbol{I}$, respectively. Arrows point to PH3-labeled cells in the MZ. J, PH3-labeled cells in the MZ were counted in a lateromedial portion of cortex (see Materials and Methods) and represented as percentage of the total number of PH3-positive cells in the VZ, SVZ, and MZ. Note the increased proportion of PH3-positive cells in the MZ at E16 ( $n=27$ sections, 3 animals) and E18 ( $n=30$ sections, 4 animals) compared with E14 ( $n=27$ sections, 4 animals) (mean \pm SEM; ${ }^{*} p<0.05$, E16vsE14; ${ }^{* * *} p<0.001$, E18vs E14; ANOVA, Tukey's post hoc test). Panels are oriented with the dorsal side of the cortex up and medial to the right. Scale bar: (in I) $A, D, G, 42 \mu \mathrm{m} ; \boldsymbol{B}, \boldsymbol{C}$,

B27, $10 \mathrm{ng} / \mathrm{ml}$ basic FGF, and $20 \mathrm{ng} / \mathrm{ml}$ epidermal growth factor (EGF) for $7 \mathrm{~d}$ as described previously (Reynolds and Weiss, 1996; Chojnacki and Weiss, 2004). Self-renewal capacity was assessed by dissociating the primary neurospheres and plating $5 \times 10^{3}$ cells in $500 \mu \mathrm{l}$ of DMEM/F-12 supplemented with B27, $10 \mathrm{ng} / \mathrm{ml}$ basic FGF, and $20 \mathrm{ng} / \mathrm{ml} \mathrm{EGF} \mathrm{(10}$ cells $/ \mu \mathrm{l})$. Neurospheres were differentiated on PDL-coated glass cover- 


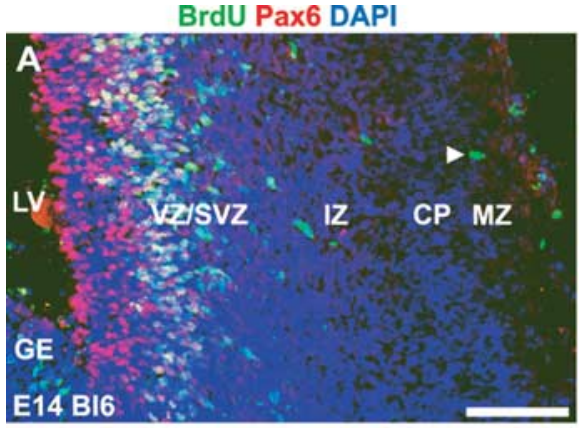

BrdU Cre DAPI

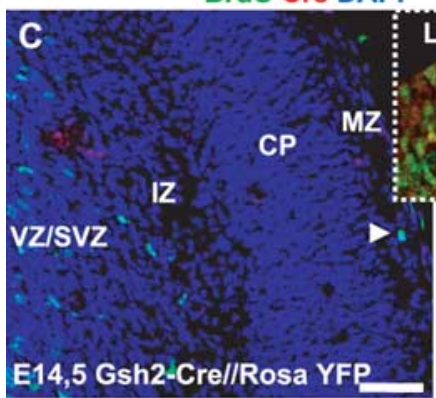

Olig2

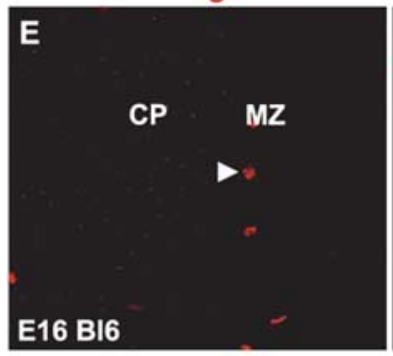

H

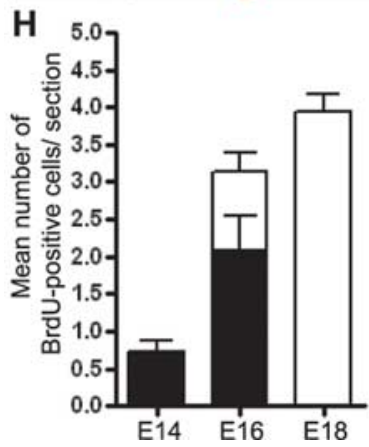

Figure 2. Marginal zone progenitors are devoid of most VZ/SVZ transcription factors and express 0lig2 in a temporally regulated manner. $\boldsymbol{A}, \boldsymbol{B}$, Coronal sections of E14 telencephalon labeled for $\operatorname{BrdU} / \operatorname{Pax} 6(\boldsymbol{A})$, $\operatorname{BrdU} / \mathrm{Tbr} 2(\boldsymbol{B})$, and stained for DAPI. Note that Pax6 is present in the VZ and Tbr2 in the SVZ, but BrdU-positive cells in the MZ are neither labeled for Pax6 (arrowhead in $A$ ) nor Tbr2 (arrowhead in B), although both colocalize with BrdU in the VZ/SVZ.C, Cre and BrdU immunolabeling in a coronal section from an E14.5 Gsh2-Cre mouse telencephalon. Note that the BrdU-positive cell in the MZ does not express (re (arrowhead in C), whereas many double-positive cells can be detected in the lateral GE (inset dashed box). $\mathbf{D}-\mathbf{G}$, Coronal section of E16 telencephalon immunostained for pan-Dlx and $\operatorname{BrdU}(\boldsymbol{D})$, Olig2 and $\operatorname{BrdU}(\boldsymbol{E}, \boldsymbol{F})$, and DAPI (D, G). Note the BrdU-positive but Dlx-negative cell in the $M Z$ ( $\boldsymbol{D}$, arrowhead), whereas many double-positive cells were detected in the lateral GE in the same section (dashed box in D). Arrowheads in $\boldsymbol{E}-\boldsymbol{G}$ indicate a cell double labeled for BrdU and 0 lig2 in the $M Z$. $\boldsymbol{H}$, Graph representing the mean number of BrdU-positive cells in the MZ that are Olig2-positive per $20 \mu \mathrm{m}$ coronal section (E14, 33 sections, 4 animals, $n=24$ cells; E16, 28 sections, 4 animals, $n=44$ cells; E18, 20 sections, 4 animals, $n=80$ cells). Note that, by E16, almost half of BrdU-positive cells are Olig2 positive, and their percentage increases to $100 \%$ by E18. LV, Lateral ventricle. Dorsal is upward and lateral is to the right. Scale bars, $50 \mu \mathrm{m}$.

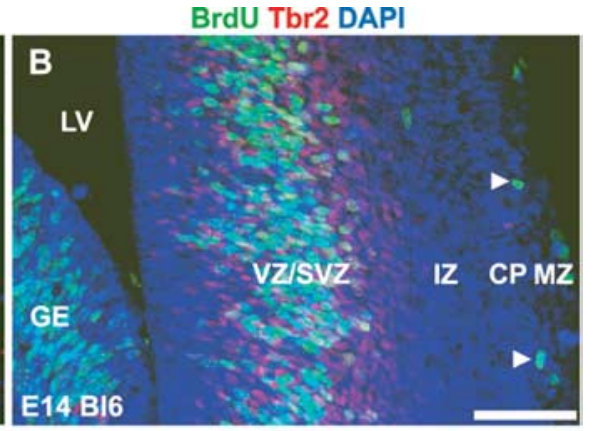

\section{BrdU DIx DAPI}

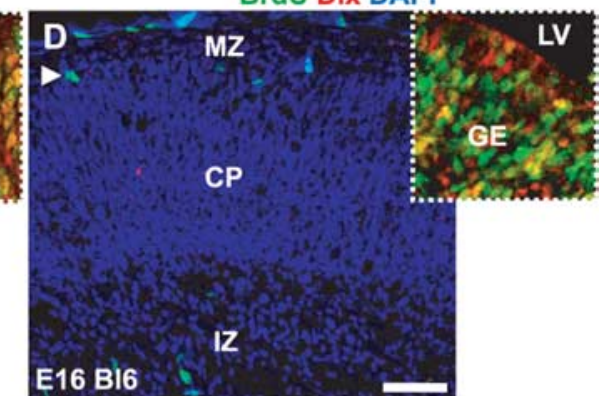

BrdU

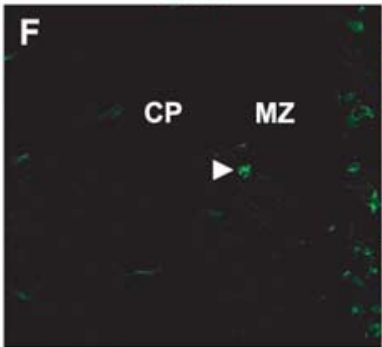

Olig2-negative

Olig2-positive

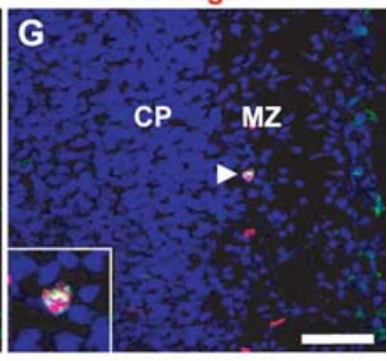
in the MZ among the total pool of PH3positive cells in the dorsal telencephalon. This proportion increased by more than double from E14 to E16 and by an additional $60 \%$ until E18, indicating an increasing contribution of $\mathrm{MZ}$ progenitors to the total pool of cortical progenitors (Fig. 1J). Noteworthy, although we found a small number of BrdU-positive cells in the cortical plate at the different stages analyzed, virtually all these cells were colabeled with the endothelial marker CD31 (supplemental Fig. 2, available at www. jneurosci.org as supplemental material). In stark contrast, only $\sim 15-20 \%$ of BrdUpositive cells in the MZ were colabeled with CD31 at E14 and E16, and virtually no $\mathrm{PH} 3 / \mathrm{CD} 31$ double-positive cell was detected in the $\mathrm{MZ}$ at those and later stages (supplemental Fig. 2, available at www.jneurosci.org as supplemental material).

To evaluate the persistence of proliferation in layer 1 , the progeny of the $\mathrm{MZ}$, we injected pups at $\mathrm{P} 0$ and $\mathrm{P} 8$ with BrdU and analyzed their brains after $1 \mathrm{~h}$ survival. Be-

slips in DMEM F-12/B27/1\% fetal calf serum. The spheres were maintained under differentiation condition for 1,3 , and $7 \mathrm{~d}$ before fixation with $4 \%$ PFA after which immunocytochemistry for neuronal and glial markers ensued. sides cells in the subventricular zone, labeled cells were also detected in layer 1 at P0 (supplemental Fig. 3, available at www.jneurosci.org as supplemental material). At this stage, BrdU- 

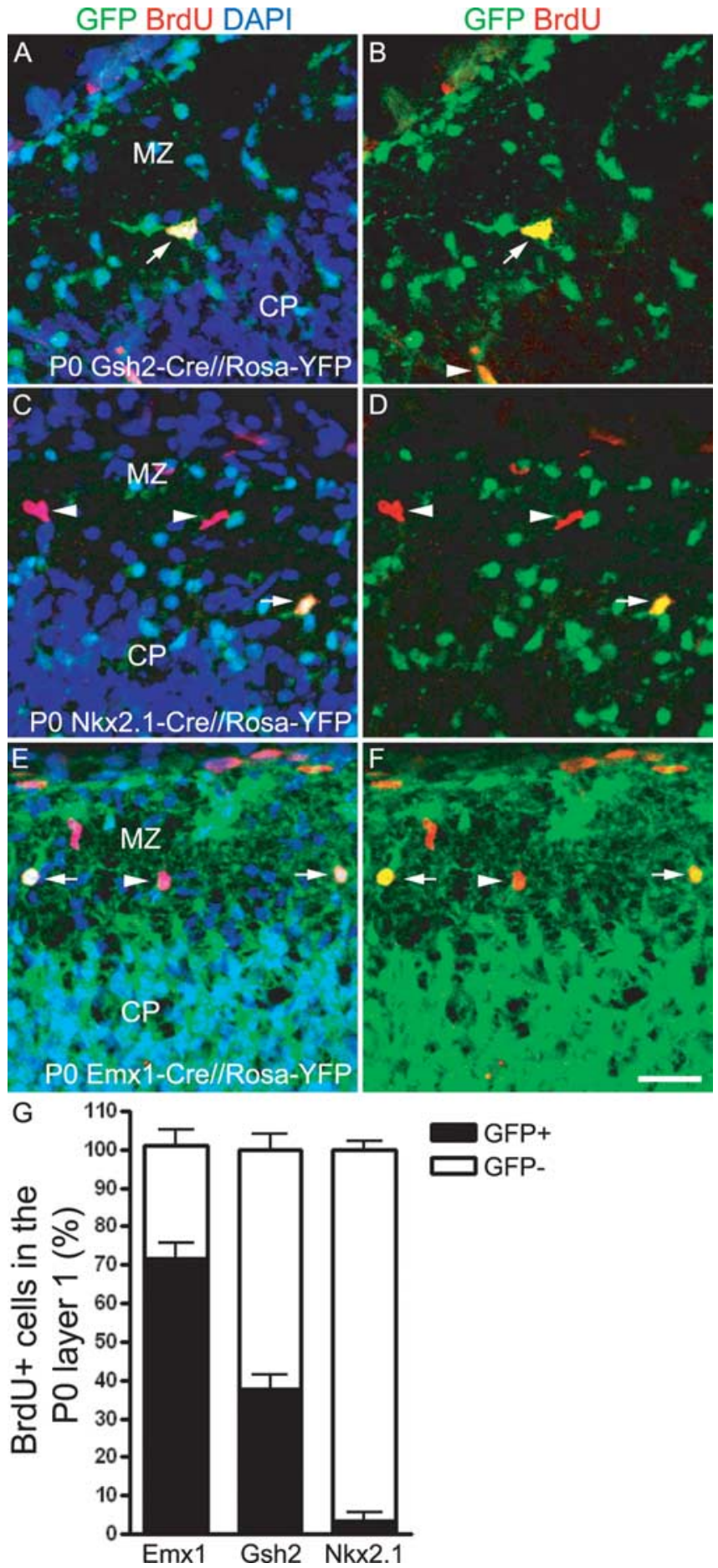

Figure 3. $M Z$ progenitors originate in distinct telencephalic regions. $\boldsymbol{A}-\boldsymbol{F}$, Coronal sections of the cortex of PO Gsh2-Cre//Rosa-YFP ( $\boldsymbol{A}, \boldsymbol{B})$, Nkx2.1-Cre//Rosa-YFP (C, D), or Emx1-Cre// Rosa-YFP $(\boldsymbol{E}, \boldsymbol{F})$ mice double labeled for BrdU (red)/GFP (green) and stained with DAPI (blue). Arrows point to cells double labeled for BrdU and GFP; arrowheads point to BrdU-positive/GFPnegative cells. G, Graph representing the proportion of BrdU-positive cells colabeled for GFP in MZ of P0 Emx1-Cre//Rosa-YFP, Gsh2-Cre//Rosa-YFP, and Nkx2.1-Cre//Rosa-YFP mice.Panels are oriented as in Figure 2. Scale bar, $25 \mu \mathrm{m}$.

positive/CD31-negative cells were also observed in the cortical layers adjacent to the subventricular zone and layer 1. Notably, hardly any BrdU-positive cells were detected in the middle cortical layers, and, when found, they were restricted to the lateralmost aspect of the cortex (supplemental Fig. 3, available at www.jneurosci.org as supplemental material). At later postnatal stages (P8), BrdU-positive cells were found scattered throughout the entire cortical parenchyma, without any preference for a given layer (supplemental Fig. 3, available at www.jneurosci.org as supplemental material), as described previously (Fujita et al., 1988).

Although cells labeled with BrdU were present in layer 1 at both neonatal and postnatal stages, we failed to observe any BrdU-positive cells in adult mouse cortex (P60) after a short BrdU pulse $(1 \mathrm{~h})$. Because cells may slow their cell cycle at later stages, we used the label-retaining protocol to detect slow dividing cells (see Materials and Methods). Indeed, the continuous supply of BrdU for 2 weeks resulted in labeled cells within all the cortical layers, including layer 1 (supplemental Fig. 3, available at www.jneurosci.org as supplemental material).

Together, our data indicate that neural progenitor cell proliferation occurs outside the main germinative zones (ventricular zone and subventricular zone) during embryonic cortical development. Although this proliferation is initially restricted to the embryonic MZ during neurogenesis, it becomes widespread in the cortical parenchyma during the first postnatal week, when cortical gliogenesis takes over.

\section{Transcription factor expression in the cells proliferating in the MZ/layer 1}

Next we asked whether the molecular features of the MZ progenitors resemble those of the VZ/SVZ during cortical neurogenesis (E13-E18). Toward this end, we examined the expression of different transcription factors, starting with Pax6 and Tbr2 that are expressed by virtually all VZ and SVZ progenitors, respectively (Götz et al., 1998; Englund et al., 2005; Cappello et al., 2006). In pronounced contrast to $\mathrm{VZ}$ and SVZ progenitors, proliferating (BrdU-positive) cells in the MZ of E14-E18 cortex contained neither Pax6 nor Tbr2 (Fig. $2 A, B$ ). Also, the transcription factors Ngn2 or Emx1 that are contained in VZ and SVZ progenitors (Schuurmans and Guillemot, 2002) could not be detected in BrdU-positive MZ cells by either direct immunostaining for the respective protein or staining for Cre-recombinase in E1-Ngn2Cre or Emx1::Cre mice (Iwasato et al., 2000; Berger et al., 2004; Cappello et al., 2006) (data not shown). Thus, these data indicate that proliferating cells in the MZ do not display the same molecular identity as other dorsal telencephalic progenitors.

To examine whether MZ progenitors express transcription factors contained in VZ/SVZ cells of the ventral telencephalon, we stained for Mash1, Dlx, Gsh2, and Olig2. At E14, these transcription factors were found to be restricted to the ventral telencephalon, and none of them colocalized with BrdU-positive cells in the cortical MZ. Although BrdU-positive cells in the MZ did not express Mash1, Gsh2, or Dlx (Fig. 2C,D and data not shown) at any of the stages analyzed, $\sim 50 \%$ of the BrdU-positive cells in the MZ were Olig2-positive at E16, with all of these doublepositive cells located in the lateral aspect of the dorsal telencephalon (Fig. 2E-G). At E18, virtually all BrdU-containing cells in the MZ expressed Olig2 (Fig. $2 H$ ). Thus, the population of MZ progenitors at E14 is negative for the transcription factors expressed by VZ/SVZ telencephalic progenitors, and the number of Olig2-positive MZ progenitors increases in a spatiotemporally regulated manner starting at E16.

The detection of Olig2 in MZ progenitors at later stages prompted us to examine whether they would actually be derived from the ventral telencephalon, the GE, or would represent an early population of cortex-derived Olig2-positive progenitors (Kessaris et al., 2006). Toward this aim, we examined the brains 


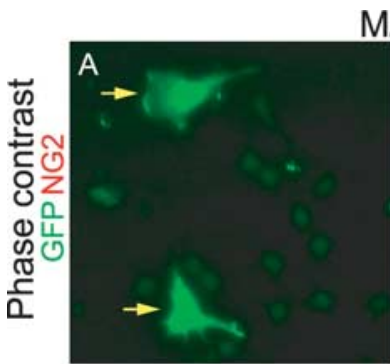

MZ/CP clones after 2DIV
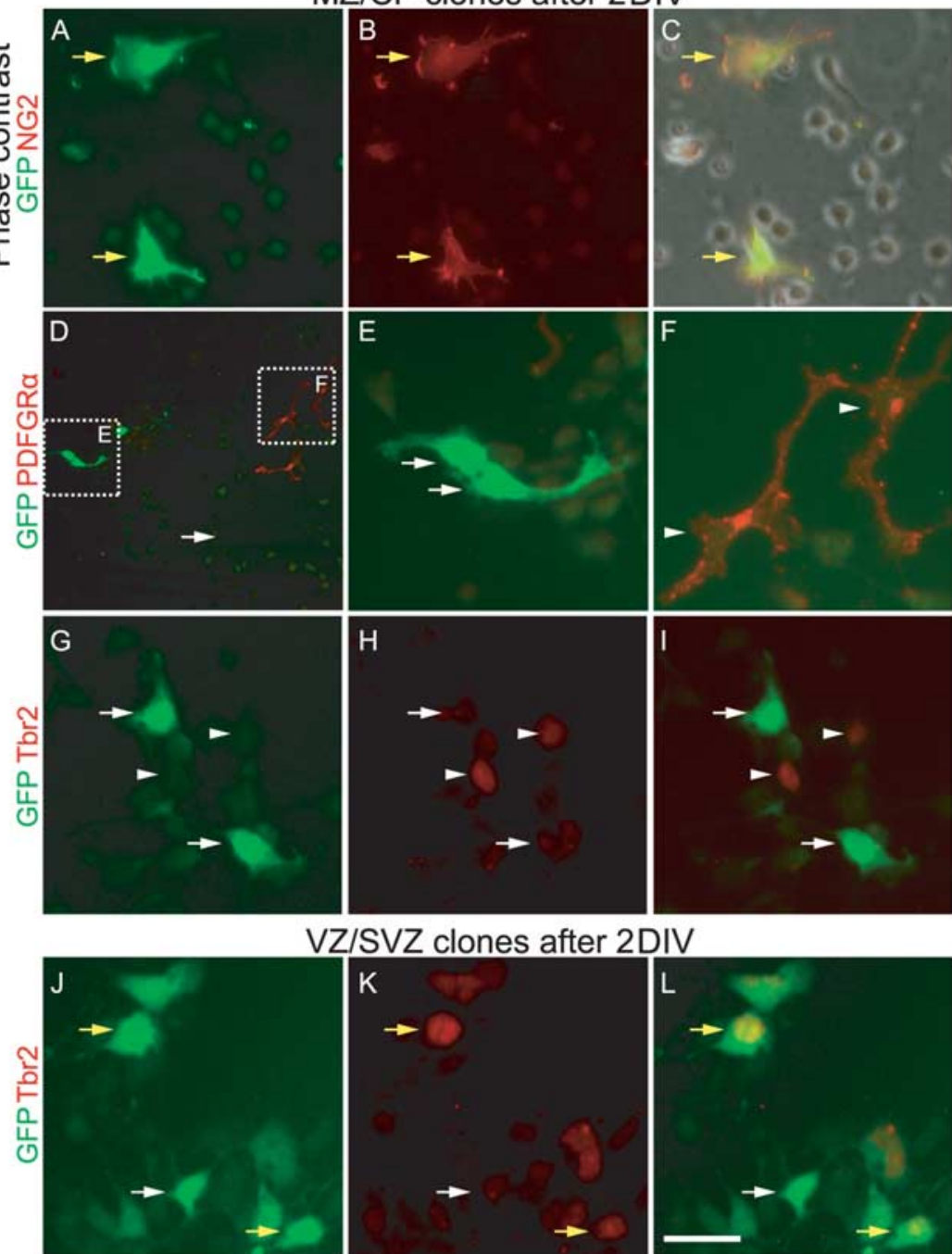

VZ/S
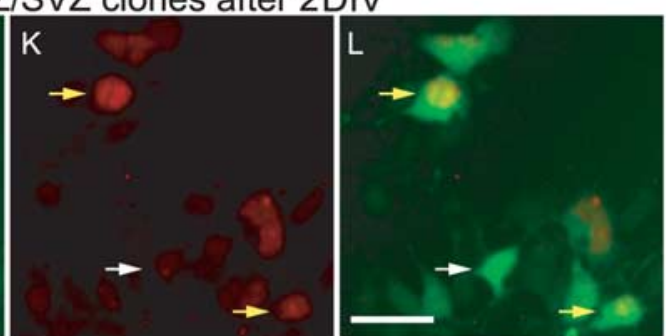

M

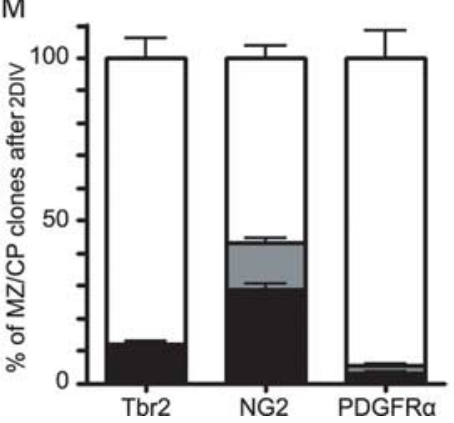

N

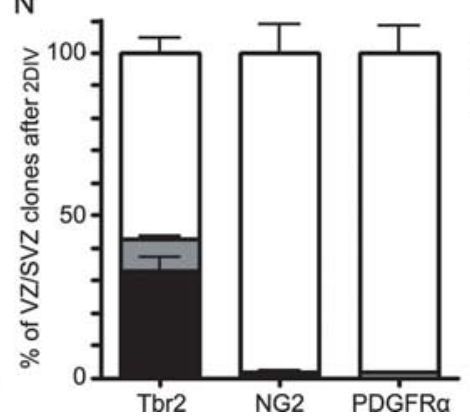

Figure 4. E15 MZ/CP progenitors differ from VZ/SVZ progenitors after 2 d in vitro. GFP-labeled clones derived from E15 cortex MZ/CP $(\boldsymbol{A}-\boldsymbol{I})$ and theVZ/SVZ( $\boldsymbol{I}-\boldsymbol{L}$ ) after 2DIV.A-C, Example of a two-cell clone (yellow arrows) double labeled for GFP (green) and NG2 (red). Note the morphology of GFP-negative cells in the same field (C). D-F, Example of GFP-positive cells ( $\boldsymbol{D}, \boldsymbol{E}$, green) in close proximity to PDGFR $\alpha$ positive cells $(\boldsymbol{D}, \boldsymbol{F}$, red). $\mathbf{G}-\boldsymbol{L}$, Examples of Tbr2-negative $(\mathbf{G}-\boldsymbol{I})$ and Tbr2-positive $(\boldsymbol{J}-\boldsymbol{L})$ dones. White arrows point to GFP-positive/Tbr2negative cells, white arrowheads to GFP-negative/Tbr2-positive cells, and yellow arrows to GFP-positive/Tbr2-positive cells. $M, N$, Graphs representing the frequency of Tbr2-, NG2-, and PDGFR $\alpha$-positive cells within GFP-positive clones derived from the E15 MZ/CP $(\boldsymbol{M})$ or the VZ/SVZ (N). Whereas many MZ/CP-derived dones contain NG2-positive cells, only a small proportion of PDGFR $\alpha$-and Tbr2-expressing cells are found in this preparation, contributing to $\sim 4$ or $12 \%$ of clones, respectively $(\boldsymbol{M})$. Conversely, VZ/SVZ-derived clones comprise a significantly higher proportion of Tbr2-positive cells but a negligible number of either NG2- or PDGFR $\alpha$-positive cells $(\boldsymbol{N})$. Also note that only the VZ/SVZ population comprises clones containing both Tbr2-positive and negative cells. Scale bar, $20 \mu \mathrm{m}$.

of P0 Gsh2-Cre//Rosa-YFP, Nkx2.1-Cre//Rosa-YFP, and Emx1-Cre//Rosa-YFP mice (Kessaris et al., 2006) after a short BrdU pulse $(1 \mathrm{~h})$. Double labeling for BrdU and GFP revealed that $\sim 30 \%$ of all proliferating cells in the layer 1 of P0 Gsh2-Cre//
Rosa-YFP mice were colabeled (Fig. $3 A, B, G$ ), indicating that those cells were derived from Gsh2-expressing cells in the GE. Some MZ progenitors were also derived from the Nkx2.1expressing progenitors located in the GE (Fig. $3 C, D, G)$. Notably, however, $\sim 70 \%$ of all proliferating cells in the MZ at P0 were generated from cortical Emx1-expressing progenitors (Fig. 3E-G). Thus, our fate mapping analyses indicate that $\mathrm{MZ} /$ layer 1 progenitors are heterogenous and originate from both dorsal and ventral telencephalon (see Discussion).

\section{Clonal analysis of the progeny derived from cells proliferating in the $\mathrm{MZ}$}

To determine the progeny of this novel precursor population, we took advantage of a well known in vitro system closely mimicking lineage decisions in vivo (Williams et al., 1991; Williams and Price, 1995). The MZ and CP were separated from the VZ, SVZ, and IZ by dissecting these zones in coronally cut slices of the E15 cortex (see Materials and Methods), so that progenitor cells isolated from the VZ/SVZ and MZ/CP fractions could be studied independently. We chose to use E15 cortex because the characteristics of the proliferating cells do not differ significantly from those at E14 (negative for the above discussed transcription factors and BrdU labeling comparable with E14), and the cellular yield was better. First, to examine the quality of this dissection, cells were fixed $2 \mathrm{~h}$ after plating them in BrdU-containing medium and were immunolabeled for BrdU and Pax6 or Tbr2, the two transcription factors labeling virtually all VZ and SVZ cells (Götz et al., 1998; Englund et al., 2005; Cappello et al., 2006), but absent from MZ precursors. Indeed, each BrdU-positive cell in the VZ/SVZ culture expressed either Pax6 (82.2 $\pm 8.6 \%)$ or Tbr2 (16.6 $\pm 4.2 \%)$. In pronounced contrast, not a single proliferating cell in the MZ culture expressed Pax 6 and $<10 \%$ contained Tbr 2 . These data indicate that the MZ/CP preparation is free of any contamination by $\mathrm{VZ}$ cells (no Pax6) and contains only few SVZ cells (Tbr2 positive), thereby confirming the reliability of the dissection method with $>90 \%$ purity. Moreover, also consistent with our findings in vivo, a negligible number of Olig2or Dlx-expressing cells were found in both VZ/ SVZ and MZ/CP preparations after $2 \mathrm{~h}$, and none of these cells were colabeled with BrdU (data not shown). In the next set of experiments, we infected the MZ/CP and VZ/SVZ cells with a low titer of GFP-containing retroviral vector (see Materials and Methods) to infect single cells undergoing mitosis. The viral titer was chosen to infect maximally 30 cells per coverslip, such that the progeny of the individual infected cells are visible as distinct cells clusters, i.e., distinct clones (Williams et al., 1991). This clonal definition was also verified by live imaging of infected cells (supplemental Fig. 4 and movie, available at 
www.jneurosci.org as supplemental material). To examine the fate of the differentiated progeny of infected cells in these experiments, we added cells from the entire E14 cortex $1 \mathrm{~d}$ later (see Materials and Methods) to obtain comparable culture conditions for both MZ/CP- and VZ/SVZderived progenitors (MZ/CP cultures on their own contain many more neurons than VZ/SVZ cultures). Control experiments showed that viral vectors were no longer infectable at the time when E14 cortical cells were added (see Materials and Methods). After 2 DIV, GFP-positive cells could be identified in small clusters containing one to six cells (Fig. 4). Although most clones contained only one or two cells, the mean number of cells per clone was higher in the VZ/SVZ $(2.2 \pm 1.3)$ than in $\mathrm{MZ} / \mathrm{CP}$ cell culture $(1.5 \pm 0.5 ; p<0.05$, unpaired $t$ test). The composition of the clones in both cultures also displayed significant differences. Clones containing Tbr2-positive cells were far more frequent in the VZ/SVZ $(>40 \%)$ than in the MZ/CP (12\%) cell culture (Fig. 4G-N), and clones containing both Tbr2-positive and -negative cells were only detected in the VZ/SVZ preparations (Fig. $4 J-N$ ). In contrast, in the $\mathrm{MZ} / \mathrm{CP}$ preparation, $>40 \%$ of clones contained NG2expressing cells (Fig. 4A-C,M), whereas a negligible proportion (1.9\%) of clones with NG2-positive cells was found in the VZ/SVZ cell culture (Fig. 4N). Finally, we observed a small proportion of clones containing PDGFR $\alpha$-positive cells in both MZ/CP (5.5\%) and VZ/SVZ (<2\%) cell culture (Fig. $4 D-F, M, N$ ). Noteworthy, in agreement with immunostaining of cells $2 \mathrm{~h}$ after dissection and in vivo, no Dlxpositive cells were detectable in either $\mathrm{MZ/CP}$ or VZ/SVZ clones. Together, these data indicate that progenitors isolated from the MZ/CP differ in their proliferative properties and molecular profile from the progenitors isolated from the VZ/SVZ.

Next, we analyzed the progeny of single $\mathrm{MZ/CP}$ and VZ/SVZ progenitors after 7-10 DIV. The cell types within each clone were identified using a combination of cell-type-specific markers in combination with anti-GFP antibodies to detect the virally transduced clones (see Materials and Methods). Three types of clones occurred in cultures derived from the MZ/CP: mixed clones, containing some GFP-positive cells colabeled with Tuj1 and others double labeled with one of the glial markers GFAP or O4 (Fig. 5A-C); pure glial clones with all GFP-positive cells in a clone either GFAP or O4 immunopositive (Fig. 5D-F and data not shown); and pure neuronal clones with all GFP-positive cells double labeled with Tuj1 (Fig. 5G-I). Consistent with previous clonal analysis of cortical progenitors, the VZ/SVZ progenitors that constitute the majority of all progenitors in the cortex genG-I, $20 \mu \mathrm{m}$.
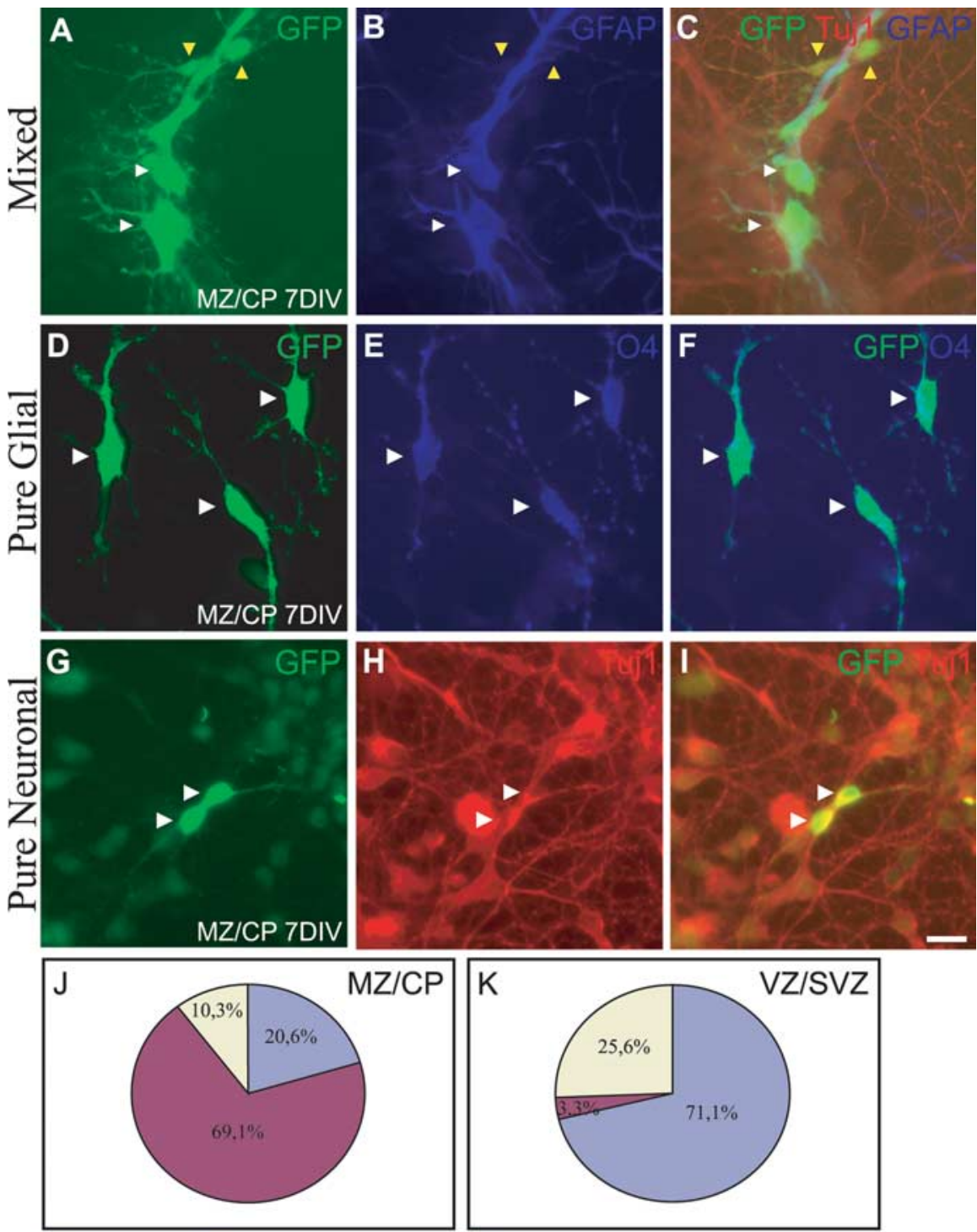

Figure 5. Progeny of clones derived from the MZ/CP or VZ/SVZ progenitor pool after $7 \mathrm{~d}$ in vitro. A-I, GFP-positive clones derived from the fraction of MZ/CP cells isolated from E15 cortex after 7 DIV. A-C, Example of a mixed clone containing cells double labeled for GFP (green) and class III $\beta$-tubulin (Tuj1) (red in C, yellow arrowheads) and cells labeled for GFP and the astrocyte marker GFAP (blue in $\boldsymbol{B}$ and $\boldsymbol{C}$, white arrowheads), which do not express Tuj1. $\boldsymbol{D}-\boldsymbol{F}$, Example of a pure glial clone with each GFP-positive cell (green in $\boldsymbol{D}$ and $\boldsymbol{F}$ ) also positive for the oligodendrocyte progenitor marker 04 (blue in $\boldsymbol{E}$ and $\boldsymbol{F}$, arrowheads). $\mathbf{G} \boldsymbol{-} \boldsymbol{I}$, Example of a pure neuronal clone containing both GFP-positive cells (green) double labeled for Tuj 1 (red). $\boldsymbol{J}-\boldsymbol{K}$, Pie diagrams depicting the percentages of pure neuronal, pure glial, and mixed clones in $\mathrm{MZ} / \mathrm{CP}(\boldsymbol{J})$ and VZ/SVZ $(\boldsymbol{K})$ cells sisolated from E15 cortex after $7 \mathrm{~d}$ in vitro (MZ/CP, $n=97 ; \mathrm{VZ} / \mathrm{SVZ}, n=100$; three independent experiments). Note that, in the MZ/CP progenitor pool, $69.1 \%$ of the clones are pure glial, among the VZ/SVZ progenitors the majority of the clones (70\%) is pure neuronal, and only $3.3 \%$ are pure glial. Among $\mathrm{MZ} / \mathrm{CP}$ clones, $30.9 \%$ comprise neurons in either purely neuronal or mixed clones. In both cases (MZ/CP and $\mathrm{VZ/SVZ),} \mathrm{mixed} \mathrm{clones} \mathrm{contain} \mathrm{either} \mathrm{astrocytes} \mathrm{or} \mathrm{oligodendrocytes} \mathrm{and} \mathrm{a} \mathrm{small} \mathrm{number} \mathrm{of} \mathrm{neurons.} \mathrm{Scale} \mathrm{bar:} \mathrm{(in} I) \boldsymbol{A}-\boldsymbol{F}, 10 \mu \mathrm{m}$;

erated up to $71 \%$ of pure neuronal clones, $25 \%$ mixed clones, and $<4 \%$ pure glial clones (Fig. $5 \mathrm{~K}$ ). In contrast, in the MZ/CP cell culture, $69 \%$ of clones were composed only of glial cells (Fig. $5 D-F, J$ ), with the majority of these being oligodendrocytes (see below). Notably, however, $\sim 20 \%$ of all MZ/CP progenitors had generated neurons only (Fig. 5G-J) and $10 \%$ had generated neurons and glial cells (mixed clones) (Fig. 5A-C,J). The neurons generated by MZ/CP progenitors do not express Calretinin or Reelin in vitro, but some were labeled by GABA and GAD65/67 antibodies (supplemental Fig. 5, available at www.jneurosci.org 


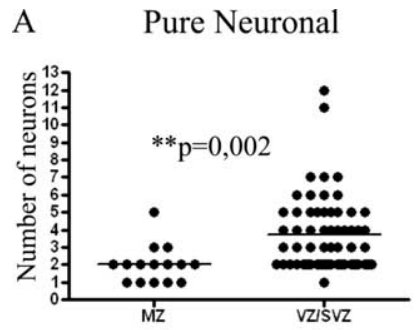

B Pure Glial
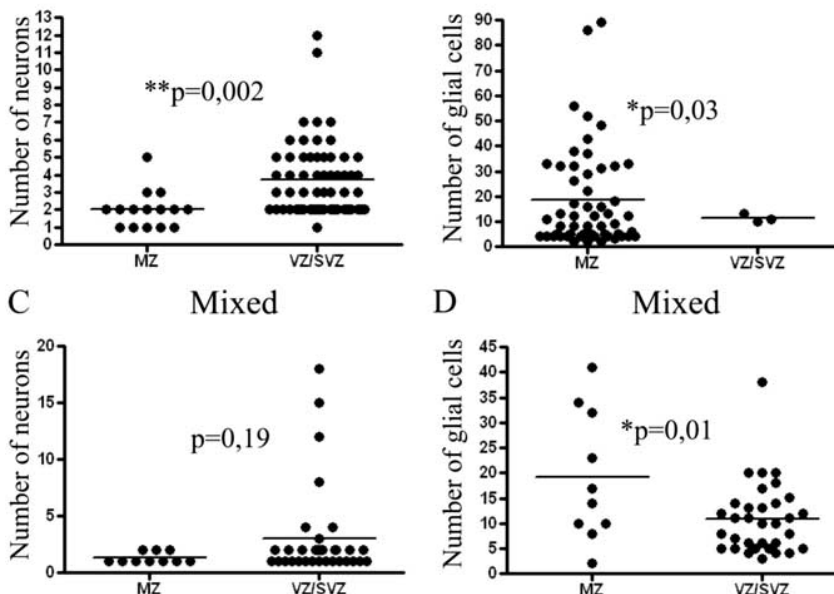

D

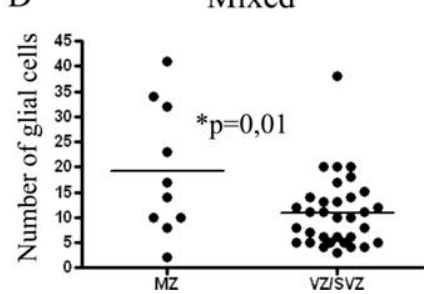

Figure 6. Size distribution of distinct clone types derived from MZ/CP or VZ/SVZ. Numbers of neurons and glia in pure neuronal $(\boldsymbol{A})$, pure glial $(\boldsymbol{B})$, and mixed clones ( $\boldsymbol{C}$ for neurons and $\boldsymbol{D}$ for glia) from MZ/CP and VZ/SVZ cells isolated from E15 cortices after 7 DIV. Note that MZ/CP progenitors generate significantly fewer neurons than VZ/SVZ progenitor in pure neuronal clones (unpaired $t$ test). Conversely, MZ/CP progenitors generate a higher number of glia in mixed and pure glial clones than VZ/SVZ.

as supplemental material) (data not shown). Thus, these data reveal a potential source of GABAergic interneurons in the developing cerebral cortex.

We further examined the clone size generated by MZ/CP and VZ/SVZ progenitors after 7-10 DIV to get a better understanding of the proliferative capacity of glial and neuronal progenitors in the two progenitor populations. Pure neuronal clones were larger, i.e., contained more neurons, when derived from VZ/SVZ progenitors compared with those derived from MZ/CP progenitors (Fig. 6A). Conversely, the number of cells was larger in the pure glial clones generated from MZ/CP than VZ/SVZ progenitors (Fig. $6 B$ ). Strikingly, both trends persisted even in the mixed clones with MZ/CP-derived mixed clones containing less neurons and more glial cells than those derived from VZ/SVZ progenitors (Fig. 6C,D). Thus, even the bipotent progenitors in the $\mathrm{MZ/CP}$ tend to generate less neurons and more glial cells compared with their counterparts in the VZ/SVZ. These findings are particularly intriguing because cells were grown in a virtually identical environment, suggesting that they differ intrinsically in their fate.

By combining immunolabeling against GFP, GFAP, and O4 (Fig. 7), we observed that both mixed and pure glial clones derived from MZ/CP $(n=33)$ and VZ/SVZ $(n=30)$ never contained GFAP- and O4-positive cells together, suggesting that, in the examined period, distinct sets of glial progenitors generating either astrocytes or oligodendrocytes were present in the MZ/CP fraction (Fig. 7A-C). These data allowed us to compare the frequency and size of astrocyte- versus oligodendrocyte-containing clones derived from MZ or VZ/SVZ glial and bipotent progenitors. Similar to previous data obtained with a mixture of all cortical progenitors (Williams et al., 1991), oligodendrocytecontaining clones were larger than astrocyte-containing clones for both MZ/CP- or VZ/SVZ-derived progeny. Strikingly, oligodendrocyte-containing clones from $\mathrm{MZ} / \mathrm{CP}$ progenitors were larger in size than those derived from VZ/SVZ progenitors, whereas MZ/CP-derived astrocyte clones tended to be smaller than those generated by VZ/SVZ progenitors (Fig. 7D,E). Together, MZ/CP progenitors in E15 mouse cerebral cortex are het- erogeneous, comprising progenitors restricted to neuronal and diverse glial lineages as well as a small proportion of progenitors with a wider potential.

\section{Progenitors in the embryonic cortical parenchyma are restricted to the $\mathrm{MZ}$}

To check whether quiescent, nonproliferating cells within the $\mathrm{CP}$ could resume proliferation in vitro, we took advantage of the neurosphere assay in which the number of progenitor cells can be expanded and often the potential to generate neurons, astrocytes, and oligodendrocytes is revealed (Reynolds and Weiss, 1996). In the first set of experiments, we compared the ability of cells derived from E15 marginal zone and cortical plate (E15 MZ/CP), E15 ventricular zone and subventricular zone (E15 VZ/SVZ), E18 marginal zone (E18 MZ), E18 cortical plate and intermediate zone (E18 CP/IZ), and E18 ventricular zone and subventricular zone (E18 VZ/SVZ) (see Materials and Methods) to generate neurospheres. After $7 \mathrm{~d}$ in neurosphere growth conditions in vitro, primary neurospheres had developed from all the preparations containing either VZ/SVZ or MZ cells but failed to develop from the E18 CP/IZ cells (Fig. 8). The frequency of neurospheres in the E15 MZ/CP was 3\% of the E15 VZ/SVZ cell cultures (Fig. $8 D$ ), consistent with the small proportion of progenitors in vivo (Fig. 1). After exposure to differentiating conditions, E15 MZ/ $\mathrm{CP}$-derived neurospheres gave rise to neuronal and glial cells (Fig. 8C) (astrocytes, $72.8 \pm 5.4 \%$; oligodendrocytes, $11.1 \pm$ 2.4\%; neurons, $16 \pm 1.4 \% ; n=20$ neurospheres, three independent experiments). Similarly, E18 MZ cells generated $\sim 5 \%$ of the number of neurospheres observed in E18 VZ/SVZ cell cultures (Fig. $8 E$ ) and also differentiated into the three major neural cell types (astrocytes, $65.6 \pm 1.2 \%$; oligodendrocytes, $21.9 \pm 1.5 \%$; neurons, $12.5 \pm 0.9 \% ; n=15$ neurospheres, two independent experiments). Thus, this analysis suggests a tight correlation between the existence of fast proliferating cells in vivo and the capacity to isolate neurosphere-forming cells from those regions. Indeed, we also found that cells isolated from all the regions of the cortical parenchyma at early postnatal (P8) stages generate primary neurospheres, in accordance with our BrdU labeling at this stage (supplemental Fig. 3, available at www.jneurosci.org as supplemental material) and previous data in the literature (Marmur et al., 1998; Belachew et al., 2003). However, although we detect slowly dividing cells in the adult cortex, no neurospheres can be derived any longer from the cortical parenchyma, including the layer 1 (data not shown).

In the next set of experiments, we analyzed the self-renewal capacity of $\mathrm{MZ}$ progenitors. Interestingly, although the E15 $\mathrm{MZ/CP}$-derived cells did not form secondary neurospheres (in two separate culture batches), these could be obtained from E18 MZ (Fig. 8 F). Thus, the E18 MZ contains progenitors with the potential to form self-renewing neurospheres, whereas the E15 MZ does not (see Discussion).

\section{Changes in the MZ progenitor pool in the Pax6 mutant Small Eye}

Progenitors are crucially influenced by their local environment, their "proliferative niche" (for review, see Alvarez-Buylla and Lim, 2004). To gain some insight into the local signals that may regulate the number of $\mathrm{MZ}$ progenitors, we examined these cells first in a mouse mutant with a large increase in the number of Reelin-positive cells in the MZ (Stoykova et al., 2003). Lack of functional Pax6 in the Pax6 ${ }^{\text {Sey }}$ (Small Eye) mice causes many defects in the developing cortex, including fate changes of $\mathrm{VZ}$ and SVZ progenitors (Götz et al., 1998; Heins et al., 2002; Englund et 
al., 2005), as well as defects in patterning, arealization, and cell migration (Chapouton et al., 1999; Stoykova et al., 2000, 2003; Yun et al., 2001; Bishop et al., 2002; Talamillo et al., 2003). Probably as a result of the increased migration of Reelin-positive cells, the number of Reelin-positive cells in the MZ of homozygous Pax $6^{\text {Sey }}$ mice is almost doubled at approximately E14 compared with the cortex of wild-type littermates (Stoykova et al., 2003). We therefore chose this stage to examine the size of the MZ progenitor pool in the $\mathrm{Pax}^{\mathrm{Sey-}-{ }^{-}} \mathrm{MZ}$. Strikingly, the proportion of BrdUpositive cells in the $\mathrm{Pax}^{\mathrm{Sey}-1-} \mathrm{MZ}$ was approximately three times higher than in wild-type littermates at E14 $(p<0.001$, Tukey's multiple comparison test) (Fig. 9). Notably, the numbers of proliferating MZ cells in the wild-type littermates closely resembled the numbers determined on mice with a different wild-type background, indicating a tight regulation of the MZ progenitor pool in wild-type cortex (compare Figs. 1E, 9C).

\section{Changes in the MZ progenitor pool in the laminin $\gamma \mathbf{1}^{-1-}$ mice}

Because the $\mathrm{MZ}$ is in close association with the basement membrane (BM) of the pia mater, we next examined whether absence of the BM may in any way affect the MZ progenitor pool as well. The basement membrane plays an important role in cortical development (Halfter et al., 2002). However, rupture of the basement membrane through targeted deletion of the $\alpha 6$ integrin, laminin $\gamma 1$ IIII, or perlecan does not affect proliferation in the VZ and SVZ (Haubst et al., 2006). To examine the potential role of basement membrane in $\mathrm{MZ}$ proliferation, we quantified the frequency of BrdU-positive cells in the MZ in the laminin $\gamma 1 \mathrm{III} 4^{-1-}$ cortex compared with wild-type littermate controls. As observed previously in wildtype animals, most BrdU-positive cells in the laminin $\gamma 1 \mathrm{III} 4^{-/-}$ MZ did not express the endothelial marker CD31 or fibronectin (data not shown), suggesting that those cells were neural progenitors. In contrast to the absence of any effect on cell proliferation within the VZ and SVZ (Haubst et al., 2006), the lack of the basement membrane promoted a significant increase in proliferation within the $\mathrm{MZ}$ as indicated by the proportion of BrdUpositive cells in this zone ( $p<0.001$, Tukey's multiple comparison test) (Fig. 9). Strikingly, proliferating cells in the MZ of laminin $\gamma 1 \mathrm{III} 4^{-1-}$ mice do not contain Pax6 or Tbr2 as the ectopically dividing cells in the cortical plate do (Haubst et al., 2006) (data not shown). Thus, the increase in proliferating cells in the MZ cannot be attributable to ectopic progenitor clusters migrating from the CP because these differ in their transcription factor expression. In agreement with previous observations, the numbers of proliferating MZ cells in the wild-type littermates were similar to mice with a different wild-type background.

\section{Discussion}

Here we characterized a novel neurogenic and gliogenic niche in the embryonic cerebral cortex. Proliferating cells in the preplate and $\mathrm{MZ}$ in vivo can be seen from the first stages of neurogenesis and further increase in number toward the end of corticogenesis.
Indeed, there is previous evidence for the occurrence of mitotic figures in the preplate and marginal zone (Raedler and Raedler, 1978; Marin-Padilla, 1985; Choi, 1988a; Valverde et al., 1995; Bystron et al., 2006). However, the total number of dividing cells in this region is much lower than in the VZ/SVZ, probably contributing to the fact that these progenitors remained uncharacterized so far. Progenitors in the MZ lacked the expression of most transcription factors characteristic for both dorsal and ventral VZ/SVZ, and only became Olig2-immunoreactive at later stages. Fate mapping experiments demonstrated that only a small proportion of proliferating cells in the $\mathrm{MZ}$ was derived from the ventral telencephalon, the Gsh2- and Nkx2.1-expressing regions (Sussel et al., 1999; Toresson et al., 2000), whereas the majority of the $\mathrm{MZ}$ progenitors was derived from the dorsal telencephalon, the Emx1-expressing region (Puelles et al., 2000). Notably, these cells comprise different sets of neuronal and glial progenitors that are distinct from the VZ/SVZ progenitors in both their potential and response to environmental changes. Thus, our results indicate that the embryonic MZ is a niche for the proliferation of both dorsally and ventrally derived progenitors and that the occurrence of proliferation in this dynamic region may contribute to the specification of different cell types in the cerebral cortex.

\section{Neurogenic potential of MZ progenitors}

Although small in size (composing 1-3\% of the progenitor pool), this population comprises a novel set of neuronal progenitors and hence represents an additional source of neuronal diversity in the cerebral cortex. Importantly, primary cultures of MZ progenitor cells have revealed a progenitor subset that generates only neurons. This is the case in the absence of added growth factors, and these progenitors are further identified as neuron-restricted progenitors by their small number of cell divisions. This clonal analysis of neurogenesis was shown to reflect the lineage of progenitor cells in vivo in a qualitative and quantitative manner 

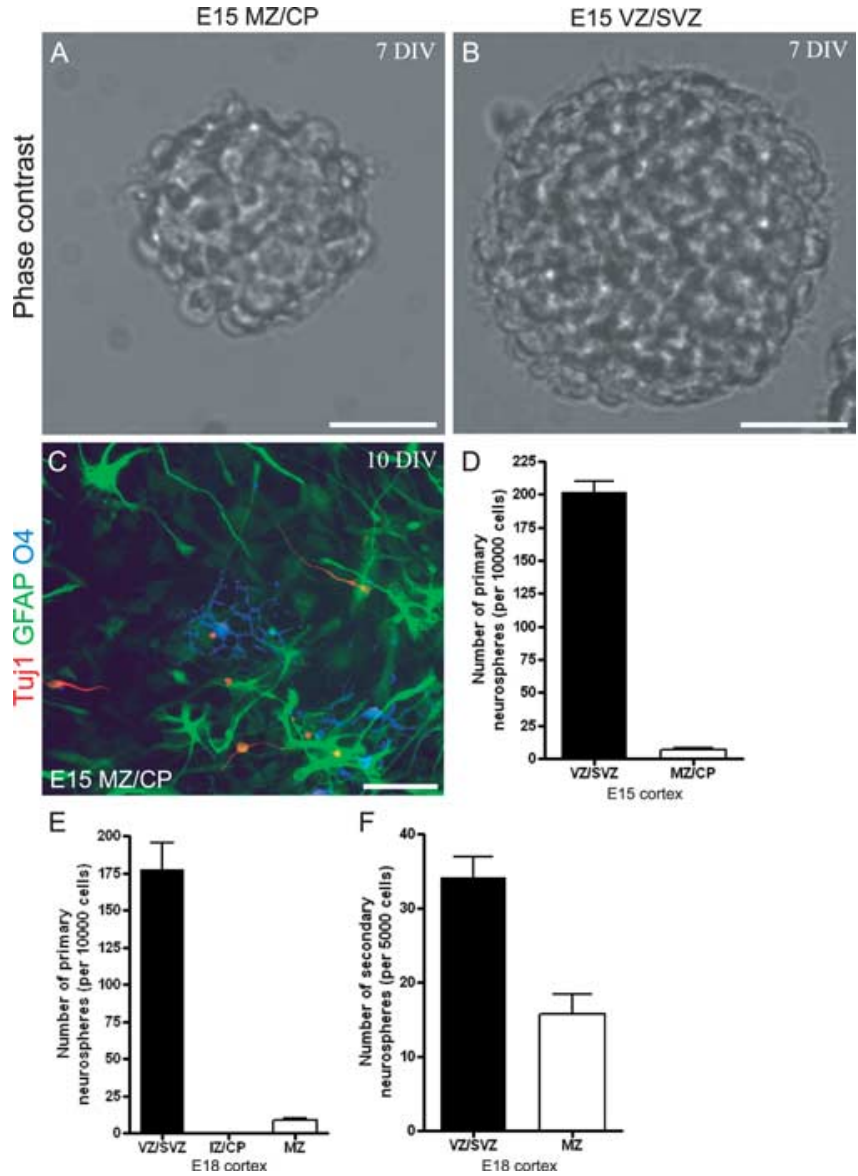

Figure 8. Multipotent progenitors are restricted to the embryonic marginal zone. Neurospheres derived from MZ/CP $(\boldsymbol{A})$ and VZ/SVZ $(\boldsymbol{B})$ fractions of E15 cortex after 7 DIV on nonadherent substrate. C, Progeny of a neurosphere derived from E15 MZ/CP after 3 DIV on adherent glass coverslips in differentiation medium. Image shows immunolabeling for 04 (blue), Tuj1 (red), and GFAP (green) showing that neurons, astrocytes, and oligodendrocytes are generated by $\mathrm{MZ} /(\mathrm{CP}$-derived neurospheres. $\boldsymbol{D}-\boldsymbol{F}$, Graphs representing the number of primary $(\boldsymbol{D}, \boldsymbol{E})$ and secondary neurospheres $(\boldsymbol{F})$ generated from E15 MZ/CP and VZ/SVZ cells (D), as well as E18 MZ and VZ/SVZ cells $(\boldsymbol{E}, \boldsymbol{F})$. Scale bars: $\boldsymbol{A}, \boldsymbol{B}, 100 \mu \mathrm{m} ; \boldsymbol{C}, 50 \mu \mathrm{m}$.

(Temple, 1989; Williams et al., 1991; Williams and Price, 1995). Thus, we believe that a subset of MZ progenitors will also generate neurons in the cortex in vivo. Because it is so far virtually impossible to label $\mathrm{MZ}$ progenitors specifically in vivo, this first evidence for a novel source of cortical neurons still awaits additional confirmation in vivo. However, it is important to point out that this primary neurogenic lineage, namely the formation of neuron-only clones in primary cell cultures lacking any growth factors, is notably different from the capacity of cells to generate neurons after culturing them as neurospheres. Many cell populations have been shown to contain small subsets that have the capacity to generate neurospheres and then give rise to a small number of neurons (Marmur et al., 1998; Kondo and Raff, 2000; Belachew et al., 2003). However, this potential is rather different from the behavior of these cells in vivo, as best illustrated by neurospheres derived from the optic nerve cells that never generate neurons in vivo (Kondo and Raff, 2000). Indeed, the neurosphere assay affects gene expression of the cultured cells and also alters their regional identity (Gabay et al., 2003; Hack et al., 2004). However, all these populations (optic nerve, postnatal cerebral cortex, etc.) do not generate neurons when exposed to primary culture conditions lacking FGF and EGF. Therefore, primary cultures reflect more closely the lineage and progeny of the

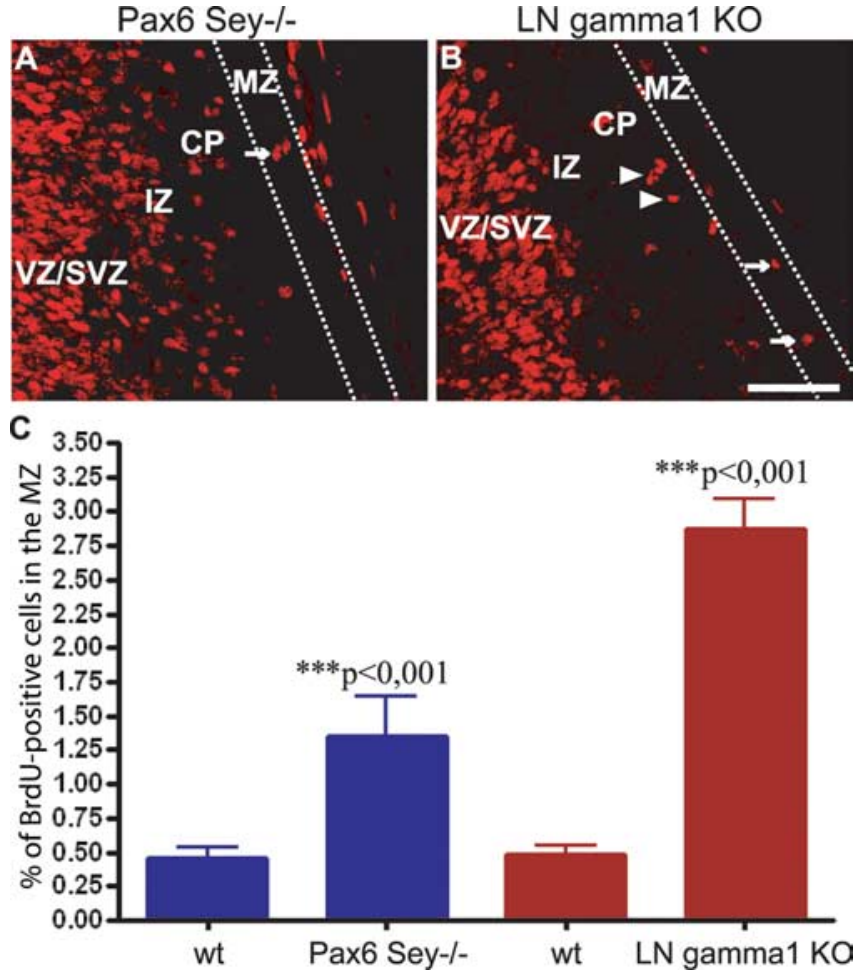

Figure 9. Increase in dividing cells in the MZ in $\mathrm{Pax} 6^{\mathrm{Sey}-/-}$ and laminin $\gamma 11114^{-1-}$ mice. BrdU immunolabeling of coronal sections of E14 cortex reveals cells in S phase (30 min after BrdU injection; $\boldsymbol{A}, \boldsymbol{B})$. Most positive cells are located in the upper VZ and SVZ. In the telencephalon of laminin $\gamma 11114^{-1-}$ mice, ectopic BrdU-positive cells are also seen in the CP (arrowheads in $\boldsymbol{B}$ ). Arrows point to BrdU-labeled cells in the $\mathrm{MZ}$ of both $\mathrm{Pax6}^{\mathrm{Sey}-/-}(\boldsymbol{A})$ and laminin $\gamma 11114^{-/-}$mice (B). Dashed lines delineate the MZ. C, Quantification of BrdU-immunolabeled cells in the MZ displays a significantly larger proportion of BrdU-positive cells in the MZ of $\mathrm{Pax}^{\mathrm{Sey}-1-}$ and laminin $\gamma 11114^{-1-}$ mice compared with their respective wild-type littermates (mean \pm SEM; ANOVA, Tukey's multiple-comparison test). LN, Laminin; KO, knock-out; wt, wild type. Scale bar, $50 \mu \mathrm{m}$.

progenitors in vivo. We therefore consider our finding of pure neuronal clones generated by a third of MZ progenitors present in primary culture conditions as evidence for a novel source of neuronal progenitors likely contributing to the generation of neurons in the cerebral cortex in vivo.

That this MZ population represents a novel source of neurons is further supported by two additional observations. First, these neuronal progenitors are distinct from the Tbr2-positive progenitors contaminating the $\mathrm{MZ} / \mathrm{CP}$ fraction, because only $10 \%$ of the progenitors are Tbr2-positive immediately after plating or $2 \mathrm{~d}$ later whereas $20 \%$ of all progenitors in these cultures generate neurons only and $10 \%$ generate neurons along with glial cells. Moreover, Tbr2-positive progenitors generate glutamatergic neurons as indeed virtually all cortical progenitors do (for review, see Hevner et al., 2006). In contrast, many neurons generated by virally infected cells in the $M Z$ cultures seemed to acquire a GABAergic identity. Interestingly, the circuitry of the MZ/layer 1 contains a heterogeneous population of GABAergic neurons (Meyer et al., 1998; Schwartz et al., 1998; Soda et al., 2003), suggesting that neurons generated by $\mathrm{MZ}$ progenitors may contribute to the intricate neuronal network in the MZ/layer 1. Consistent with our data, previous reports have described a small proportion of progenitors isolated from the embryonic cerebral cortex that generate GABAergic neurons (Götz et al., 1995; He et al., 2001; Yung et al., 2002). Fate mapping experiments indicated that cortical GABAergic neurons are not generated from Emx1- 
expressing progenitors (Gorski et al., 2002), suggesting that the neuronal progenitors isolated from the E15 MZ could be contained within the $30 \%$ of these progenitors originating ventrally according to our fate mapping analysis.

\section{Bipotent and early glia-restricted progenitors in the $\mathrm{MZ}$}

A marked feature of $\mathrm{MZ}$ progenitors is their capacity for generating large clones of glial cells in early corticogenesis. Astrocytes and oligodendrocytes derived from bipotent (neuron/glial) or glial-restricted progenitors compose the largest population of $\mathrm{MZ}$ progenitors at E15. These are 20 times more frequent than astrocyte or oligodendrocyte progenitors from the same developmental stage in the VZ/SVZ cultures. The VZ/SVZ results are in agreement with previous studies showing the predominance of neuronal precursors at these early ages (Williams et al., 1991; Davis and Temple, 1994), a marked contrast to the lineage profile found in the MZ. Therefore, both this cell lineage analyses and the increased proliferation observed in the $\mathrm{MZ}$ at later corticogenesis indicate that the MZ may be an important source for astrocytes and oligodendrocytes, which may provide a different coverage of cerebral cortex tissue than VZ/SVZ progenitors. Studies from the developing human cerebral cortex suggest a dual origin for astroglial cells, namely from the VZ and MZ (Marin-Padilla, 1995; deAzevedo et al., 2003). The latter study described that most astrocytes in SVZ/intermediate zone of the human cerebral cortex appear to have derived from the transformation of radial glia into astrocytes. However, transforming figures with a radial process were never found in the surface of the cortex, and a bistratified organization of astrocytes was seen from early on. This idea is also in line with the progression of GFAP staining during rodent cortical development (Choi, 1988a) and is intriguing in regard to astroglia heterogeneity in the adult brain (Emsley and Macklis, 2006). Furthermore, $M Z$ progenitors could also contribute to the dorsal sources of cortical oligodendrocytes arising at later stages (Kessaris et al., 2006). Thus, our discovery of early fate-restricted oligodendrocyte and astrocyte progenitor cells in the MZ may provide a source of specific glial subtypes in the cerebral cortex, which may contribute differentially to the glial composition of cerebral cortex.

\section{Embryonic cortical progenitors outside the VZ/SVZ are restricted to the $\mathrm{MZ}$}

By using the neurosphere assay, we demonstrated that only the cell fractions containing either the embryonic VZ/SVZ or MZ give rise to multipotent neurospheres, supporting the view that the CP does not contain neural progenitor cells that can be activated to divide at this stage. These data therefore support the view that the cell lineages described in our E15 clonal analyses of $\mathrm{MZ/CP}$ are indeed derived from MZ progenitors. Notably, consistent with the lack of Olig2 expression in MZ progenitors at early developmental stages, E15 MZ/CP cells fail to form selfrenewing neurospheres that can only be obtained from E18 MZ progenitors after the appearance of Olig2 expression. The acquisition of Olig2 may well be responsible for the ability to form self-renewing neurospheres, because Olig2 is required for neurosphere proliferation and self-renewal (Hack et al., 2004).

\section{Regulation of MZ progenitors within their niche in vivo}

Two defining characteristics of the MZ environment are its close proximity to the BM (Halfter et al., 2002) and the presence of a specific neuronal population synthesizing the glycoprotein Reelin (Tissir and Goffinet, 2003). Notably, both of these features have been shown to play an important role in germinative niches
(Kim et al., 2002; Mercier et al., 2002; Alvarez-Buylla and Lim, 2004). Indeed these factors also seem to have a potent influence on the progenitor pool within the $\mathrm{MZ}$ as it is significantly increased in the $\mathrm{Pax}_{6} \mathrm{Sey-1-}^{\mathrm{S}}$ an laminin $\gamma 1 \mathrm{IIII} 4^{-/-}$cortex. In the former, there is a significant increase in the number of Reelinproducing cells (Stoykova et al., 2003), whereas the latter display a severe disruption of the basement membrane (Haubst et al., 2006), suggesting that cellular and extracellular changes in the MZ might modulate cell proliferation within this zone. These data therefore further underline the crucial differences in proliferation, fate restriction, and response to extrinsic signals between $\mathrm{MZ}$ - and VZ/SVZ-derived progenitors.

\section{References}

Alvarez-Buylla A, Lim DA (2004) For the long run: maintaining germinal niches in the adult brain. Neuron 41:683-686.

Anderson SA, Eisenstat DD, Shi L, Rubenstein JL (1997) Interneuron migration from basal forebrain to neocortex: dependence on Dlx genes. Science 278:474-476.

Ang Jr ES, Haydar TF, Gluncic V, Rakic P (2003) Four-dimensional migratory coordinates of GABAergic interneurons in the developing mouse cortex. J Neurosci 23:5805-5815.

Belachew S, Chittajallu R, Aguirre AA, Yuan X, Kirby M, Anderson S, Gallo V (2003) Postnatal NG2 proteoglycan-expressing progenitor cells are intrinsically multipotent and generate functional neurons. J Cell Biol 161:169-186.

Berger J, Eckert S, Scardigli R, Guillemot F, Gruss P, Stoykova A (2004) E1-Ngn2/Cre is a new line for regional activation of Cre recombinase in the developing CNS. Genesis 40:195-199.

Berry M, Rogers AW (1965) The migration of neuroblasts in the developing cerebral cortex. J Anat 99:691-709.

Bishop KM, Rubenstein JL, O’Leary DD (2002) Distinct actions Emx1, Emx2, and Pax6 in regulating the specification of areas in the developing neocortex. J Neurosci 22:7627-7638.

Bystron I, Rakic P, Molnar Z, Blakemore C (2006) The first neurons of the human cerebral cortex. Nat Neurosci 9:880-886.

Cappello S, Attardo A, Wu X, Iwasato T, Itohara S, Wilsch-Brauninger M, Eilken HM, Rieger MA, Schroeder TT, Huttner WB, Brakebusch C, Götz M (2006) The Rho-GTPase cdc42 regulates neural progenitor fate at the apical surface. Nat Neurosci 9:1099-1107.

Caviness Jr VS, Sidman RL (1973) Time of origin or corresponding cell classes in the cerebral cortex of normal and reeler mutant mice: an autoradiographic analysis. J Comp Neurol 148:141-151.

Chapouton P, Gartner A, Götz M (1999) The role of Pax6 in restricting cell migration between developing cortex and basal ganglia. Development 126:5569-5579.

Choi BH (1988a) Prenatal gliogenesis in the developing cerebrum of the mouse. Glia 1:308-316.

Choi BH (1988b) Developmental events during the early stage of cerebral cortical neurogenesis in man. A correlative light, electron microscopic, immunohistochemical and Golgi study. Acta Neuropathol 75:441-447.

Chojnacki A, Weiss S (2004) Isolation of a novel platelet-derived growth factor-responsive precursor from the embryonic ventral forebrain. J Neurosci 24:10888-10899.

Davis AA, Temple S (1994) A self-renewing multipotential stem cell in embryonic rat cerebral cortex. Nature 372:263-266.

deAzevedo LC, Fallet C, Moura-Neto V, Daumas-Duport C, Hedin-Pereira C, Lent R (2003) Cortical radial glial cells in human fetuses: depthcorrelated transformation into astrocytes. J Neurobiol 55:288-298.

Del Rio JA, Heimrich B, Borrell V, Forster E, Drakew A, Alcantara S, Nakajima K, Miyata T, Ogawa M, Mikoshiba K, Derer P, Frotscher M, Soriano E (1997) A role for Cajal-Retzius cells and reelin in the development of hippocampal connections. Nature 385:70-74.

Emsley JG, Macklis JD (2006) Astroglial heterogeneity closely reflects the neuronal-defined anatomy of the adult murine CNS. Neuron Glia Biol 2:175-186.

Englund C, Fink A, Lau C, Pham D, Daza RA, Bulfone A, Kowalczyk T, Hevner RF (2005) Pax6, Tbr2, and Tbr1 are expressed sequentially by radial glia, intermediate progenitor cells, and postmitotic neurons in developing neocortex. J Neurosci 25:247-251.

Friauf E, Shatz CJ (1991) Changing patterns of synaptic input to subplate 
and cortical plate during development of visual cortex. J Neurophysiol 66:2059-2071.

Fujita T, Yoshimine T, Hayakawa T, Ushio Y, Takemoto O, Maruno M, Kano M, Mogami H (1988) Postnatal cell proliferation in the rat cerebrum: immunohistochemical study with bromodeoxyuridine (BrdU) (in Japanese). No To Shinkei 40:651-655.

Gabay L, Lowell S, Rubin LL, Anderson DJ (2003) Deregulation of dorsoventral patterning by FGF confers trilineage differentiation capacity on CNS stem cells in vitro. Neuron 40:485-499.

Ghosh A, Shatz CJ (1992) Involvement of subplate neurons in the formation of ocular dominance columns. Science 255:1441-1443.

Gorski JA, Talley T, Qiu M, Puelles L, Rubenstein JL, Jones KR (2002) Cortical excitatory neurons and glia, but not GABAergic neurons, are produced in the Emx1-expressing lineage. J Neurosci 22:6309-6314.

Götz M, Bolz J (1992) Formation and preservation of cortical layers in slice cultures. J Neurobiol 23:783-802.

Götz M, Williams BP, Bolz J, Price J (1995) The specification of neuronal fate: a common precursor for neurotransmitter subtypes in the rat cerebral cortex in vitro. Eur J Neurosci 7:889-898.

Götz M, Stoykova A, Gruss P (1998) Pax6 controls radial glia differentiation in the cerebral cortex. Neuron 21:1031-1044.

Hack MA, Sugimori M, Lundberg C, Nakafuku M, Götz M (2004) Regionalization and fate specification in neurospheres: the role of Olig2 and Pax6. Mol Cell Neurosci 25:664-678.

Halfter W, Dong S, Yip YP, Willem M, Mayer U (2002) A critical function of the pial basement membrane in cortical histogenesis. J Neurosci 22:6029-6040.

Haubensak W, Attardo A, Denk W, Huttner WB (2004) Neurons arise in the basal neuroepithelium of the early mammalian telencephalon: a major site of neurogenesis. Proc Natl Acad Sci USA 101:3196-3201.

Haubst N, Berger J, Radjendirane V, Graw J, Favor J, Saunders GF, Stoykova A, Götz M (2004) Molecular dissection of Pax6 function: the specific roles of the paired domain and homeodomain in brain development. Development 131:6131-6140.

Haubst N, Georges-Labouesse E, De Arcangelis A, Mayer U, Götz M (2006) Basement membrane attachment is dispensable for radial glial cell fate and for proliferation, but affects positioning of neuronal subtypes. Development 133:3245-3254.

He W, Ingraham C, Rising L, Goderie S, Temple S (2001) Multipotent stem cells from the mouse basal forebrain contribute GABAergic and oligodendrocytes to the cerebral cortex during embryogenesis. J Neurosci 21:8854-8862.

Hedin-Pereira C, deMoraes EC, Santiago MF, Mendez-Otero R, Lent R (2000) Migrating neurons cross a reelin-rich territory to form an organized tissue out of embryonic cortical slices. Eur J Neurosci 12:4536-4540.

Hendzel MJ, Wei Y, Mancini MA, Van Hooser A, Ranalli T, Brinkley BR, Bazzet-Jones DP, Allis CD (1997) Mitosis-specific phosphorylation of histone $\mathrm{H} 3$ initiates primarily within periocentromeric heterochromatin during G2 and spreads in a ordered fashion coincident with mitotic chromosome condensation. Chromosoma 106:348-360.

Heins N, Malatesta P, Cecconi F, Nakafuku M, Tucker KL, Hack MA, Chapouton P, Barde YA, Götz M (2002) Glial cells generate neurons: the role of the transcription factor Pax6. Nat Neurosci 5:308-315.

Hevner RF, Hodge RD, Daza RA, Englund C (2006) Transcription factors in glutamatergic neurogenesis: conserved programs in neocortex, cerebellum, and adult hippocampus. Neurosci Res 55:223-233.

Iwasato T, Datwani A, Wolf AM, Nishiyama H, Taguchi Y, Tonegawa S, Knopfel T, Erzurumlu RS, Itohara S (2000) Cortex-restricted disruption of NMDAR1 impairs neuronal patterns in the barrel cortex. Nature 406:726-731.

Kessaris N, Fogarty M, Iannarelli P, Grist M, Wegner M, Richardson WD (2006) Competing waves of oligodendrocytes in the forebrain and postnatal elimination of an embryonic lineage. Nat Neurosci 9:173-179.

Kim HM, Qu T, Kriho V, Lacor P, Smalheiser N, Pappas GD, Guidotti A, Costa E, Sugaya K (2002) Reelin function in neural stem cell biology. Proc Natl Acad Sci USA 99:4020-4025.

Kondo T, Raff M (2000) Oligodendrocyte precursor cells reprogrammed to become multipotential CNS stem cells. Science 289:1754-1757.

Lavdas AA, Grigoriou M, Pachnis V, Parnavelas JG (1999) The medial ganglionic eminence gives rise to a population of early neurons in the developing cerebral cortex. J Neurosci 19:7881-7888.
Letinic K, Zoncu R, Rakic P (2002) Origin of GABAergic neurons in the human neocortex. Nature 417:645-649.

Levison SW, Goldman JE (1993) Both oligodendrocytes and astrocytes develop from progenitors in the subventricular zone of postnatal rat forebrain. Neuron 10:201-212.

Levison SW, Chuang C, Abramson BJ, Goldman JE (1993) The migrational patterns and developmental fates of glial precursors in the rat subventricular zone are temporally regulated. Development 119:611-622.

Malatesta P, Hack MA, Hartfuss E, Kettenmann H, Klinkert W, Kirchhoff F, Götz M (2003) Neuronal or glial progeny: regional differences in radial glia fate. Neuron 37:751-764.

Marin-Padilla M (1978) Dual origin of the mammalian neocortex and evolution of the cortical plate. Anat Embryol (Berl) 152:109-126.

Marin-Padilla M (1985) Early vascularization of the embryonic cerebral cortex: Golgi and electron microscopic studies. J Comp Neurol 241:237-249.

Marin-Padilla M (1995) Prenatal development of fibrous (white matter), protoplasmic (gray matter), and layer I astrocytes in the human cerebral cortex: a Golgi study. J Comp Neurol 357:554-572.

Marmur R, Mabie PC, Gokhan S, Song Q, Kessler JA, Mehler MF (1998) Isolation and developmental characterization of cerebral cortical multipotent progenitors. Dev Biol 204:577-591.

McConnell SK, Ghosh A, Shatz CJ (1989) Subplate neurons pioneer the first axon pathway from the cerebral cortex. Science 245:978-982.

Mercier F, Kitasako JT, Hatton GI (2002) Anatomy of the brain neurogenic zones revisited: fractones and the fibroblast/macrophage network. J Comp Neurol 451:170-188.

Meyer G, Soria JM, Martinez-Galan JR, Martin-Clemente B, Fairen A (1998) Different origins and developmental histories of transient neurons in the marginal zone of the fetal and neonatal rat cortex. J Comp Neurol 397:493-518.

Miyata T, Kawaguchi A, Saito K, Kawano M, Muto T, Ogawa M (2004) Asymmetric production of surface-dividing and non-surface-dividing cortical progenitor cells. Development 131:3133-3145.

Nieto M, Monuki ES, Tang H, Imitola J, Haubst N, Khoury SJ, Cunningham J, Götz M, Walsh CA (2004) Expression of Cux-1 and Cux-2 in the subventricular zone and upper layers II-IV of the cerebral cortex. J Comp Neurol 479:168-180.

Noctor SC, Martinez-Cerdeno V, Ivic L, Kriegstein AR (2004) Cortical neurons arise in symmetric and asymmetric division zones and migrate through specific phases. Nat Neurosci 7:136-144.

Nowakowski RS, Lewin SB, Miller MW (1989) Bromodeoxyuridine immunohistochemical determination of the lengths of the cell cycle and the DNA-synthetic phase for an anatomically defined population. J Neurocytol 18:311-318.

Price J, Thurlow L (1988) Cell lineage in the rat cerebral cortex: a study using retroviral-mediated gene transfer. Development 104:473-482.

Puelles L, Kuwana E, Puelles E, Bulfone A, Shimamura K, Keleher J, Smiga S, Rubenstein JL (2000) Pallial and subpallial derivatives in the embryonic chick and mouse telencephalon, traced by the expression of the genes Dlx-2, Emx-1, Nkx-2.1, Pax-6, and Tbr-1. J Comp Neurol 424:409-438.

Raedler E, Raedler A (1978) Autoradiographic study of early neurogenesis in rat neocortex. Anat Embryol (Berl) 154:267-284.

Rakic P (1972) Mode of cell migration to the superficial layers of fetal monkey neocortex. J Comp Neurol 145:61-83.

Reynolds BA, Weiss S (1996) Clonal and population analyses demonstrate that an EGF-responsive mammalian embryonic CNS precursor is a stem cell. Dev Biol 175:1-13.

Schuurmans C, Guillemot F (2002) Molecular mechanisms underlying cell fate specification in the developing telencephalon. Curr Opin Neurobiol 12:26-34

Schwartz TH, Rabinowitz D, Unni V, Kumar VS, Smetters DK, Tsiola A, Yuste R (1998) Networks of coactive neurons in developing layer 1. Neuron 20:541-552.

Soda T, Nakashima R, Watanabe D, Nakajima K, Pastan I, Nakanishi S (2003) Segregation and coactivation of developing neocortical layer 1 neurons. J Neurosci 23:6272-6279.

Srinivas S, Watanabe T, Lin CS, William CM, Tanabe Y, Jessell TM, Costantini F (2001) Cre reporter strains produced by targeted insertion of EYFP and ECFP into the ROSA26 locus. BMC Dev Biol 1:4.

Stoykova A, Treichel D, Hallonet M, Gruss P (2000) Pax6 modulates the 
dorsoventral patterning of the mammalian telencephalon. J Neurosci 20:8042-8050.

Stoykova A, Hatano O, Gruss P, Götz M (2003) Increase in reelin-positive cells in the marginal zone of Pax6 mutant mouse cortex. Cereb Cortex 13:560-571.

Sussel L, Marin O, Kimura S, Rubenstein JL (1999) Loss of Nkx2.1 homeobox gene function results in a ventral to dorsal molecular respecification within the basal telencephalon: evidence for a transformation of the pallidum into the striatum. Development 126:3359-3370.

Talamillo A, Quinn JC, Collinson JM, Caric D, Price DJ, West JD, Hill RE (2003) Pax6 regulates regional development and neuronal migration in the cerebral cortex. Dev Biol 255;151-163.

Tanaka DH, Maekawa K, Yanagawa Y, Obata K, Murakami F (2006) Multidirectional and multizonal tangential migration of GABAergic interneurons in the developing cerebral cortex. Development 133:2167-2176.

Tekki-Kessaris N, Woodruff R, Hall AC, Gaffield W, Kimura S, Stiles CD, Rowitch DH, Richardson WD (2001) Hedgehog-dependent oligodendrocyte lineage specification in the telencephalon. Development 128:2545-2554.

Temple S (1989) Division and differentiation of isolated CNS blast cells in microculture. Nature 340:471-473.

The Boulder Committee (1970) Embryonic vertebrate central nervous system: revised terminology. Anat Rec 166:257-261.

Tissir F, Goffinet AM (2003) Reelin and brain development. Nat Rev Neurosci 4:496-505.

Toresson H, Potter SS, Campbell K (2000) Genetic control of dorsal-ventral identity in the telencephalon: opposing roles for Pax6 and Gsh2. Development 127:4361-4371.

Valverde F, De Carlos JA, Lopez-Mascaraque L (1995) Time of origin and early fate of preplate cells in the cerebral cortex of the rat. Cereb Cortex 5:483-493.

Walsh C, Cepko CL (1988) Clonally related cortical cells show several migration patterns. Science 241:1342-1345.

Williams BP, Price J (1995) Evidence for multiple precursor cell types in the embryonic rat cerebral cortex. Neuron 14:1181-1188.

Williams BP, Read J, Price J (1991) The generation of neurons and oligodendrocytes from a common precursor cell. Neuron 7:685-693.

Wichterle H, Turnbull DH, Nery S, Fishell G, Alvarez-Buylla A (2001) In utero fate mapping reveals distinct migratory pathways and fates of neurons born in the mammalian basal forebrain. Development 128:3759-3771.

Wu SX, Goebbels S, Nakamura K, Kometani K, Minato N, Kaneko T, Kave KA, Tamamaki N (2005) Pyramidal neurons of upper cortical layers generated by NEX-positive progenitor cells in the subventricular zone. Proc Natl Acad Sci USA 102:17172-17177.

Yun K, Potter S, Rubenstein JL (2001) Gsh2 and Pax6 play complementary roles in dorsoventral patterning of the mammalian telencephalon. Development 128:193-205.

Yung SY, Gokhan S, Jurcsak J, Molero AE, Abrajano JJ, Mehler MF (2002) Differential modulation of BMP signaling promotes the elaboration of cerebral cortical GABAergic neurons or oligodendrocytes from a common sonic hedgehog-responsive ventral forebrain progenitor species. Proc Natl Acad Sci USA 99:16273-16278. 